\title{
BMJ Open Outcome reporting from clinical trials of non-valvular atrial fibrillation treated with traditional Chinese medicine or Western medicine: a systematic review
}

\author{
Ruijin Qiu, ${ }^{1}$ Jiayuan $\mathrm{Hu},{ }^{1}$ Ya Huang, ${ }^{1}$ Songjie Han, ${ }^{1}$ Changming Zhong, ${ }^{1}$ Min Li, ${ }^{1}$
} Tianmai He, ${ }^{1}$ Yiyi Lin, ${ }^{1}$ Manke Guan, ${ }^{1}$ Jing Chen, ${ }^{2}$ Hongcai Shang ${ }^{1,3}$

To cite: Qiu R, Hu J, Huang Y, et al. Outcome reporting from clinical trials of non-valvular atrial fibrillation treated with traditional Chinese medicine or Western medicine: a systematic review. BMJ Open 2019;9:e028803. doi:10.1136/ bmjopen-2018-028803

- Prepublication history and additional material for this paper are available online. To view these files, please visit the journal online (http://dx.doi. org/10.1136bmjopen-2018028803).

$\mathrm{RQ}$ and $\mathrm{JH}$ contributed equally.

Received 28 December 2018 Revised 22 June 2019 Accepted 09 July 2019

Check for updates

(c) Author(s) (or their employer(s)) 2019. Re-use permitted under CC BY-NC. No commercial re-use. See rights and permissions. Published by BMJ.

For numbered affiliations see end of article.

Correspondence to

Jing Chen; cjshcsyc@126.com

Hongcai Shang;

shanghongcai@foxmail.com

\section{ABSTRACT}

Objectives To examine variation in outcomes, outcome measurement instruments (OMls) and measurement times in clinical trials of non-valvular atrial fibrillation (NVAF) and to identify outcomes for prioritisation in developing a core outcome set (COS) in this field.

Design This study was a systematic review.

Data sources Clinical trials published between January 2015 and March 2019 were obtained from PubMed, the Cochrane Library, Web of Science, Wanfang Database, the China National Knowledge Infrastructure and SinoMed.

Eligibility criteria Randomised controlled trials (RCTs) and observational studies were considered. Interventions included traditional Chinese medicine and Western medicine. The required treatment duration or followup time was $\geq 4$ weeks. The required sample size was $\geq 30$ and $\geq 50$ in each group in RCTs and observational studies, respectively. We excluded trials that aimed to investigate the outcome of complications of NVAF, to assess the mechanisms or pharmacokinetics, or for which full text could not be acquired.

Data extraction and synthesis The general information and outcomes, OMls and measurement times were extracted. The methodological and outcome reporting quality were assessed. The results were analysed by descriptive analysis.

Results A total of 218 articles were included from 25255 articles. For clinical trials of antiarrhythmic therapy, 69 outcomes from 16 outcome domains were reported, and $28(31.82 \%, 28 / 88)$ outcomes were reported only once; the most frequently reported outcome was ultrasonic cardiogram. Thirty-one outcomes (44.93\%, 31/69) were provided definitions or OMls; the outcome measurement times ranged from 1 to 20 with a median of 3 . For clinical trials of anticoagulation therapy, 82 outcomes from 18 outcome domains were reported; 38 (29.23\%, 38/130) outcomes were reported only once. The most frequently reported outcome was ischaemic stroke. Forty $(48.78 \%$, 40/82) outcomes were provided OMls or definitions; and the outcome measurement times ranged from 1 to 27 with a median of 8 .

Conclusion Outcome reporting in NVAF is inconsistent. Thus, developing a COS that can be used in clinical trials is necessary.
Strengths and limitations of this study

- This systematic review is the first to describe variation in outcomes, outcome measurement instruments and outcome measurement time reporting in clinical trials for non-valvular atrial fibrillation (NVAF).

- The methodology is reproducible and transparent and has been assessed during a peer-review process.

- English and Chinese databases were searched, and randomised controlled trials and observational studies were considered.

- The aim of this review was to provide a list of outcomes for clinical trials of NVAF in traditional Chinese medicine, which is focused on Chinese herbal medicine therapy. Thus, clinical trials of surgery were not considered.

\section{INTRODUCTION}

According to a systematic review, atrial fibrillation $(\mathrm{AF})$ is the main contributor to many diseases, such as ischaemic heart disease, stroke, renal disease and peripheral arterial disease. In addition, AF usually results in major cardiovascular events, cardiovascular and all-cause mortality, and sudden cardiac death. ${ }^{1}$ Thus, treating AF is important.

There are different kinds of classifications for AF. According to the aetiology, AF can be classified as isolated $\mathrm{AF}$, valvular $\mathrm{AF}$, non-valvular AF (NVAF) and so on. NVAF refers to AF occurring without rheumatic mitral stenosis, mechanical/bioprosthetic or mitral valve repair. ${ }^{2}$ According to the characteristics and timing of $\mathrm{AF}$ onset, $\mathrm{AF}$ can be classified as first diagnosed $\mathrm{AF}$, paroxysmal $\mathrm{AF}$, persistent $\mathrm{AF}$, long-standing persistent $\mathrm{AF}$ and permanent $\mathrm{AF}^{3}$

Current evidence has shown that catheter ablation and drug therapy are beneficial for controlling heart rhythm, maintaining ventricular rate, and preventing thrombosis and stroke. However, the arrhythmogenic 


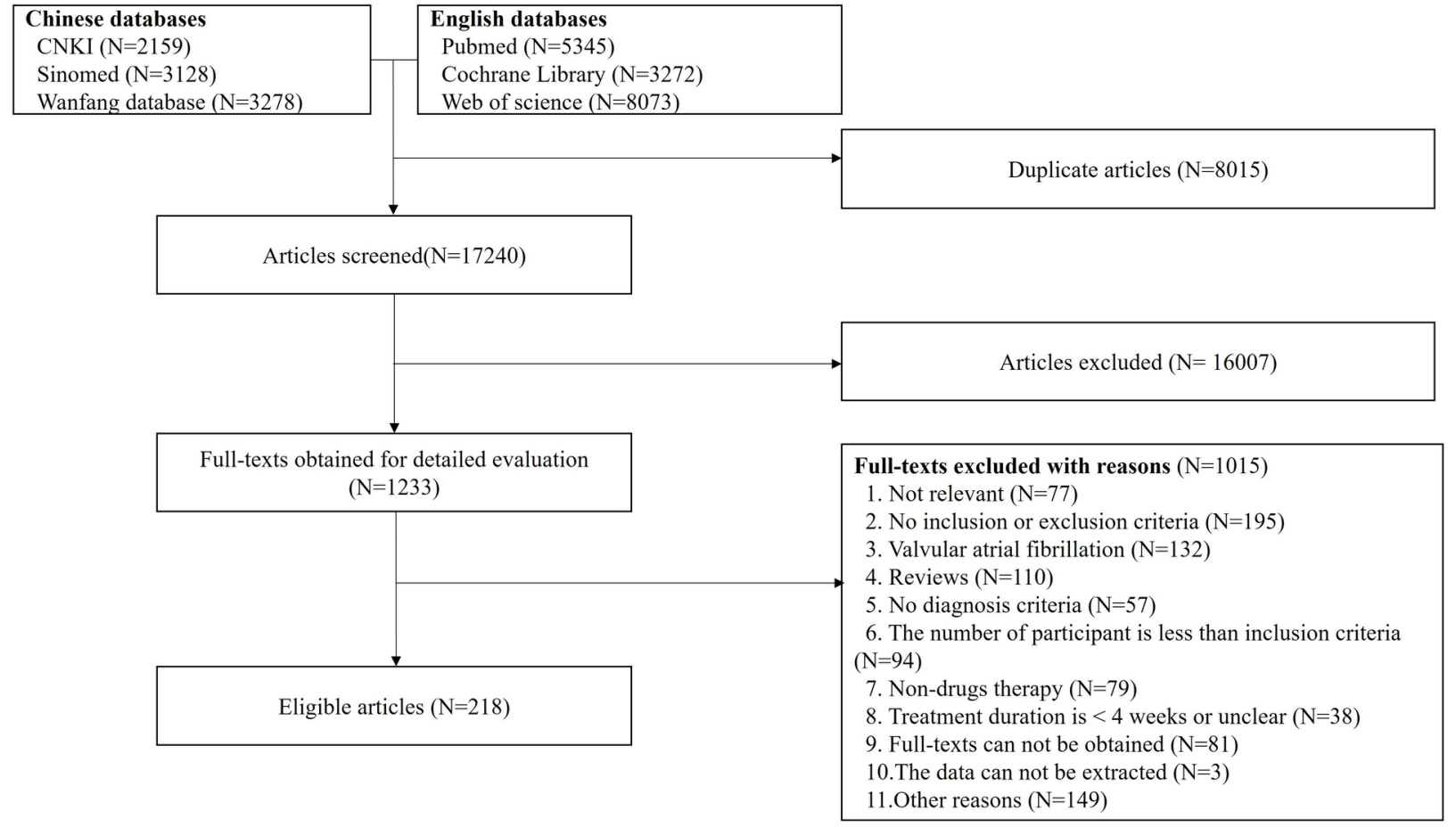

Figure 1 The flowchart of the systematic review.

effects and risk of death after taking antiarrhythmic drugs cannot be ignored. With the increasing number of traditional Chinese medicine (TCM) clinical trials in treating AF, the efficacy and safety of TCM have been proven. ${ }^{4}$ However, there are some problems in these TCM clinical trials; for example, similar clinical trials reported different outcomes. Therefore, some trials cannot be included in systematic reviews/meta-analyses because of outcome reporting heterogeneity. In TCM clinical trials, the long-term outcomes, patient-reported outcomes and safety outcome reporting are limited; thus, these trials cannot provide appropriate evidence for TCM in treating AF. Developing a core outcome set (COS) may resolve these problems.

A COS is a minimum set that should be measured and reported in all clinical trials for a specific condition. ${ }^{5}$ According to the characteristics and advantages of TCM, we intend to develop a COS for TCM clinical trials for NVAF, with registered ${ }^{6}$ and published ${ }^{7}$ protocols.

According to the study protocol, conducting a systematic review is the first step in the development of a COS for NVAF to develop a long list of outcomes. In this research, we will report the results of the systematic review, including assessing the quality of outcome reporting and the quality of trials, as well as examining the variation in outcome reporting, outcome measurement instrument (OMI) reporting and measurement time point reporting.

\section{METHODS}

\section{Search strategy}

In clinical trials and clinical practice, TCM, especially Chinese herbal medicine therapy is often used as an adjuvant therapy in internal medicine treatment; thus, obtaining a comprehensive list of outcomes for TCM clinical trials is difficult. In this systematic review, we focused on clinical trials of TCM, integrated medicine and Western medicine in internal medicine. The literature database included PubMed, the Cochrane Library, Web of Science, Wanfang database, the China National Knowledge Infrastructure and SinoMed. A literature search was conducted two times. The first search was conducted from January 2015 to June 2017, and the second search was conducted from May 2017 to March 2019. The search strategy for English databases is shown in online supplementary additional file 1 .

\section{Inclusion criteria}

According to the protocol, both randomised controlled trials (RCTs) and observational studies were considered. Patients with NVAF who accepted interventions including TCM or Western medicines were eligible. The required treatment duration or follow-up time was $\geq 4$ weeks. For RCTs, the required number of participants was $\geq 30$ in each group. For observational studies, the required number of participants was $\geq 50$.

\section{Exclusion criteria}

We excluded clinical trials that aimed to investigate the outcome of complications of NVAF, to assess the mechanism of drug action or pharmacokinetics, or for which full text could not be acquired.

Methodological quality has little influence on developing a long list of outcomes in the development of a COS. However, we excluded some studies with serious problems, such as a Jadad score of 0 for RCTs, contradictions 

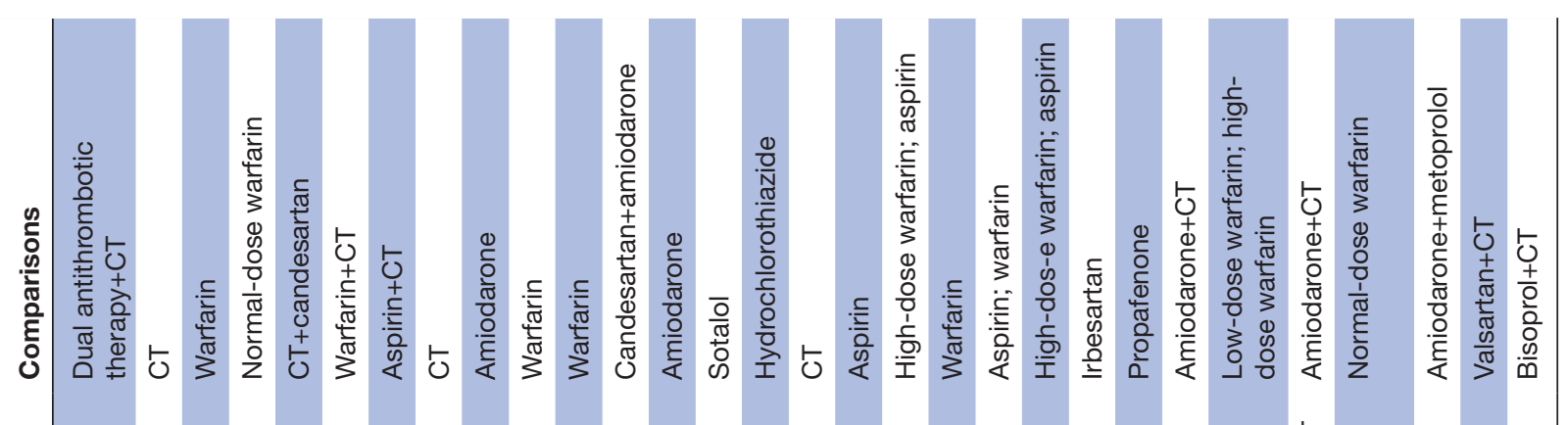

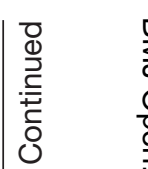

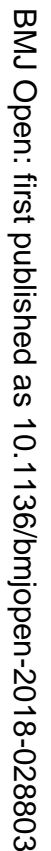

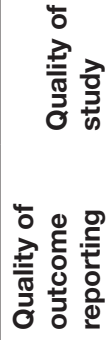

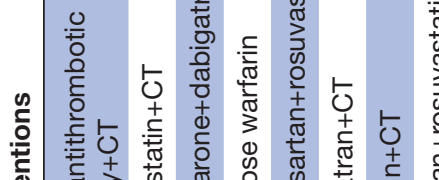

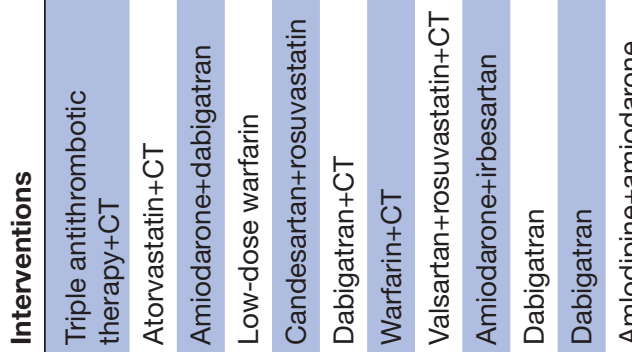

$\frac{\sqrt{0}}{\frac{0}{0}} \frac{0}{\frac{\pi}{0}}$

:

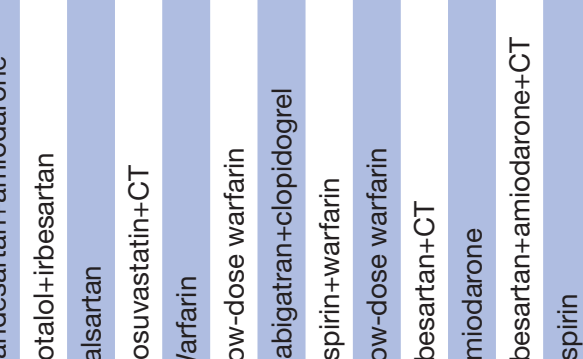

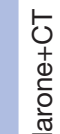

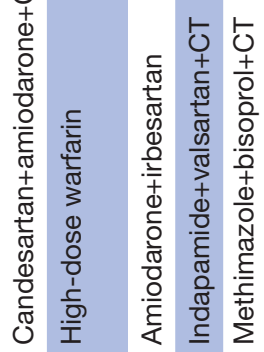

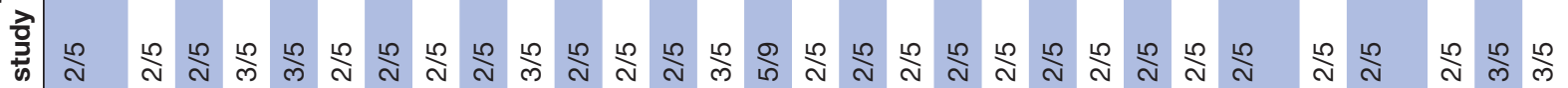

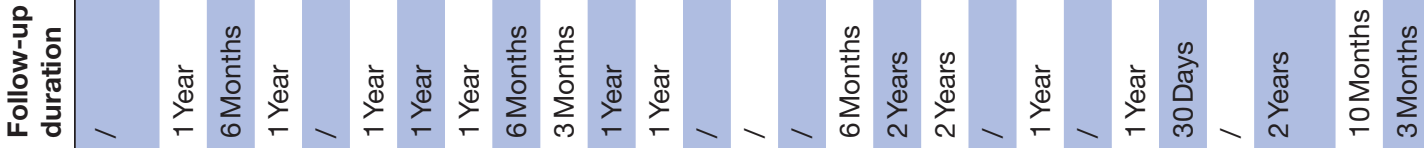

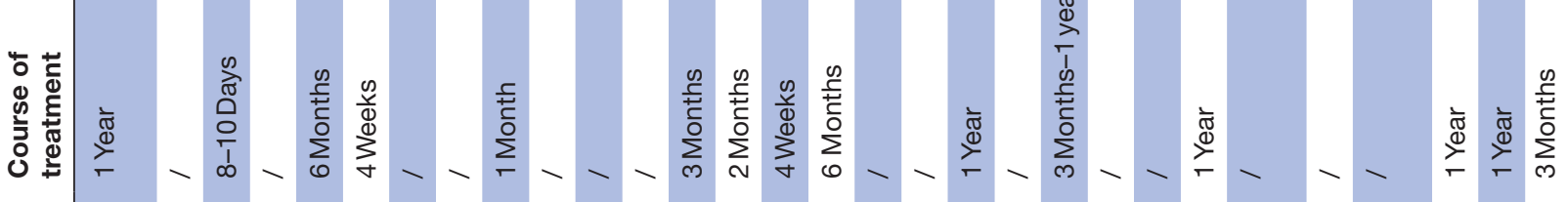

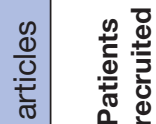

$\frac{0}{0}$
0

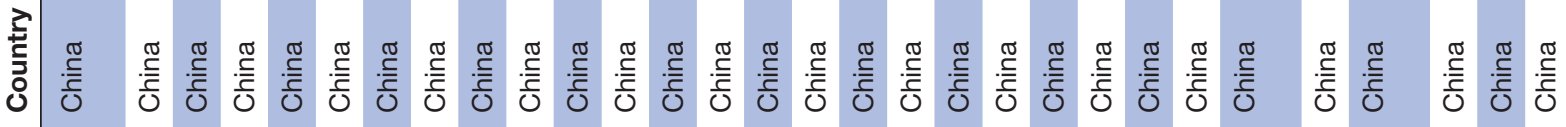

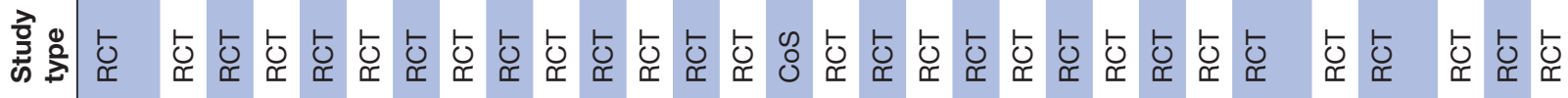




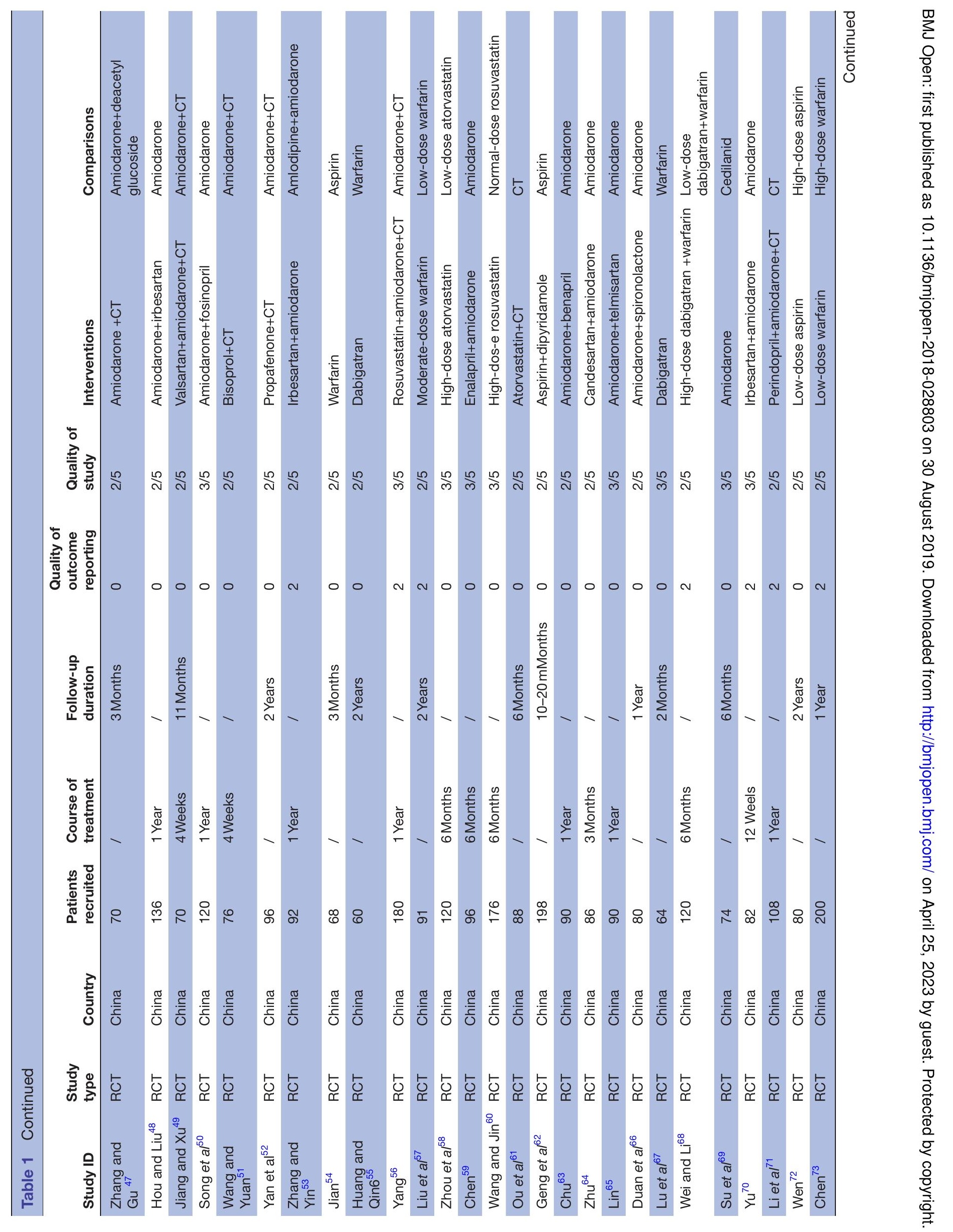



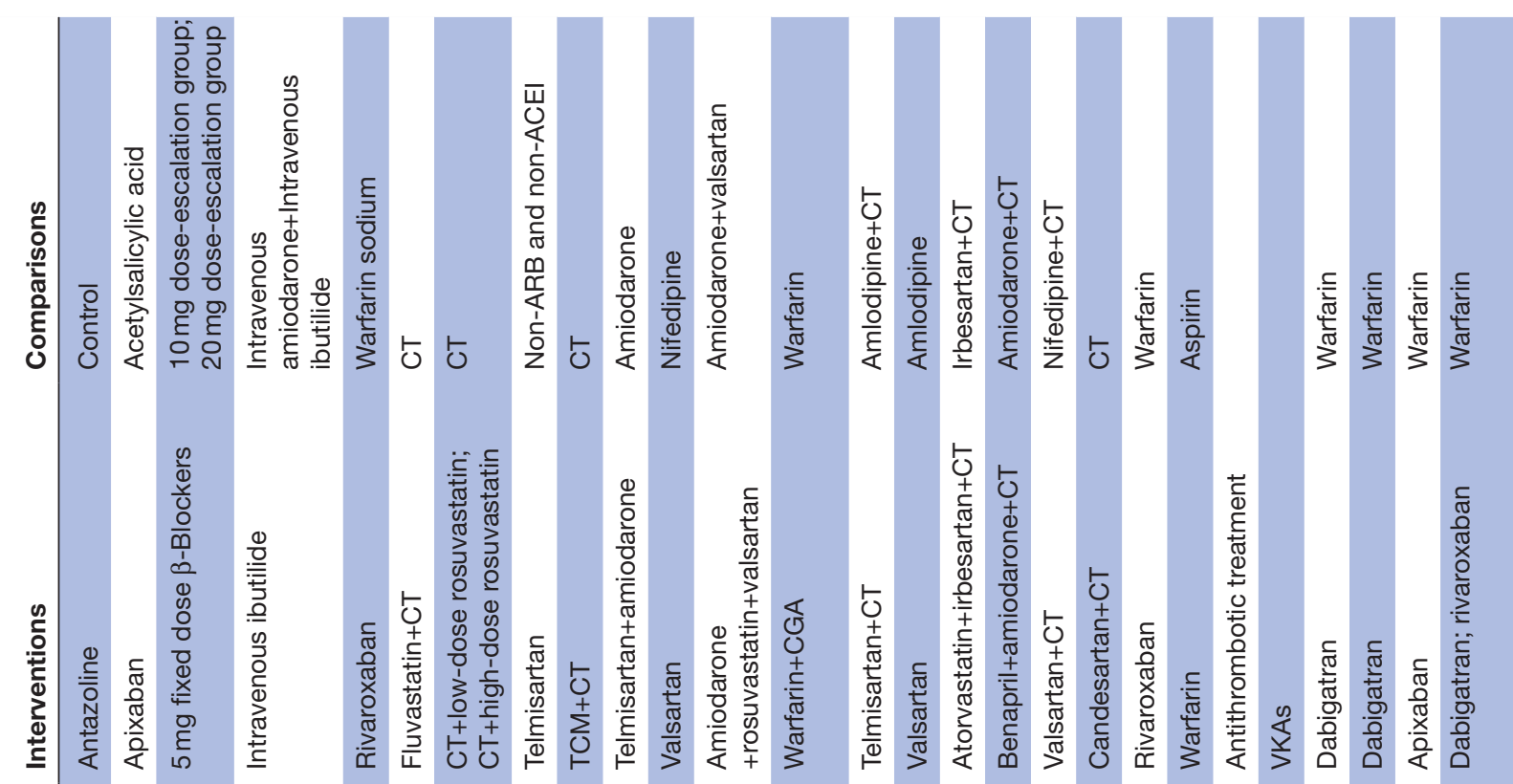

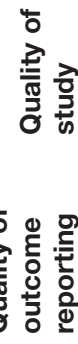

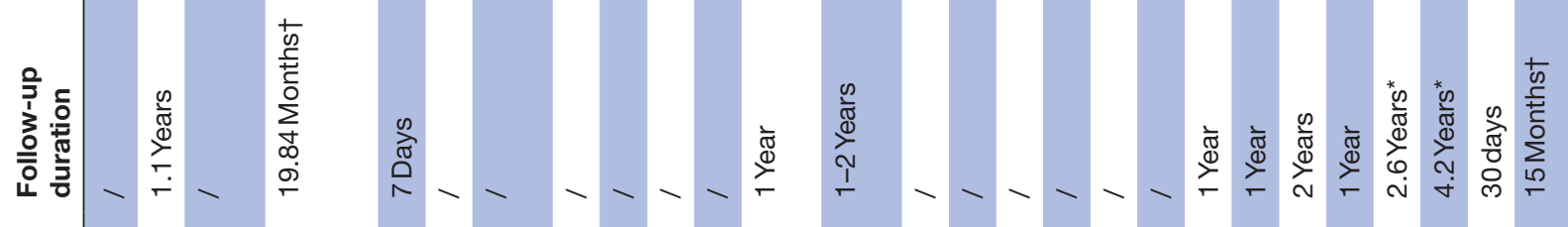

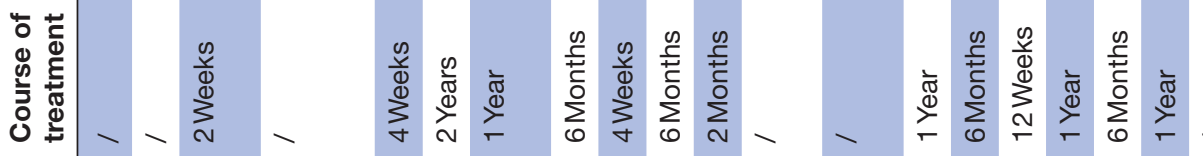

完

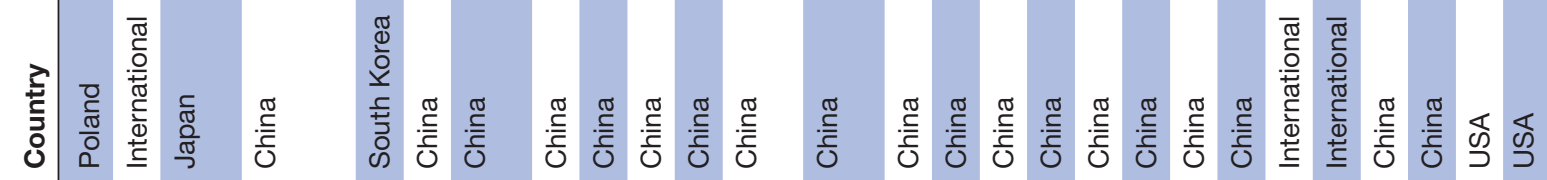

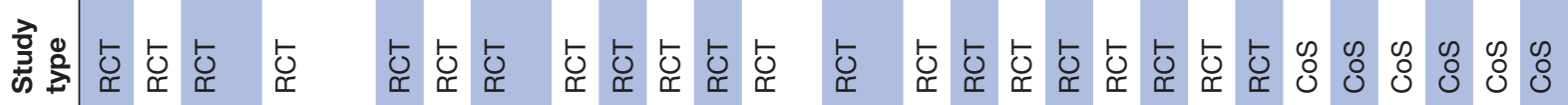

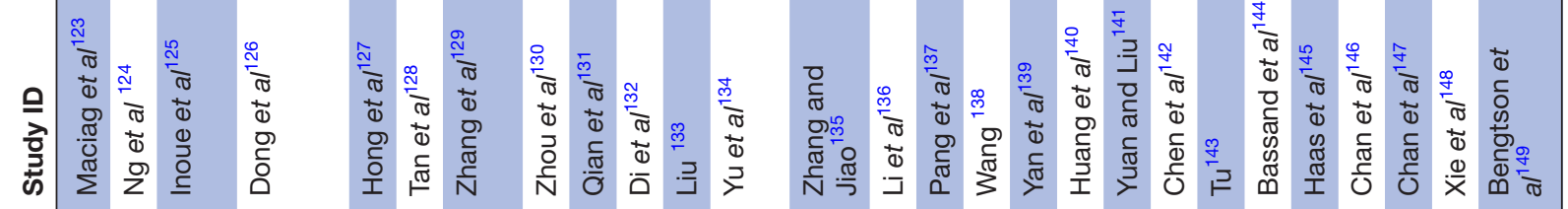




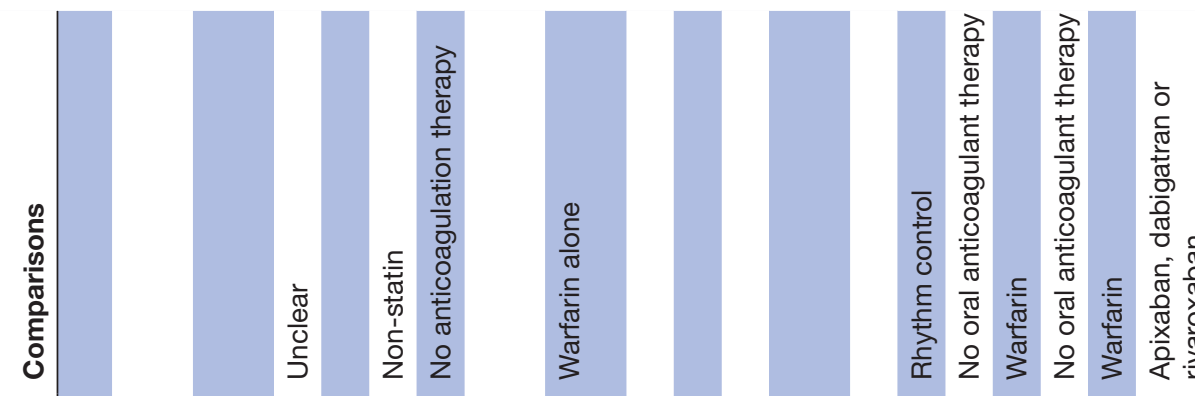

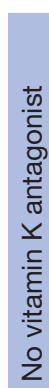

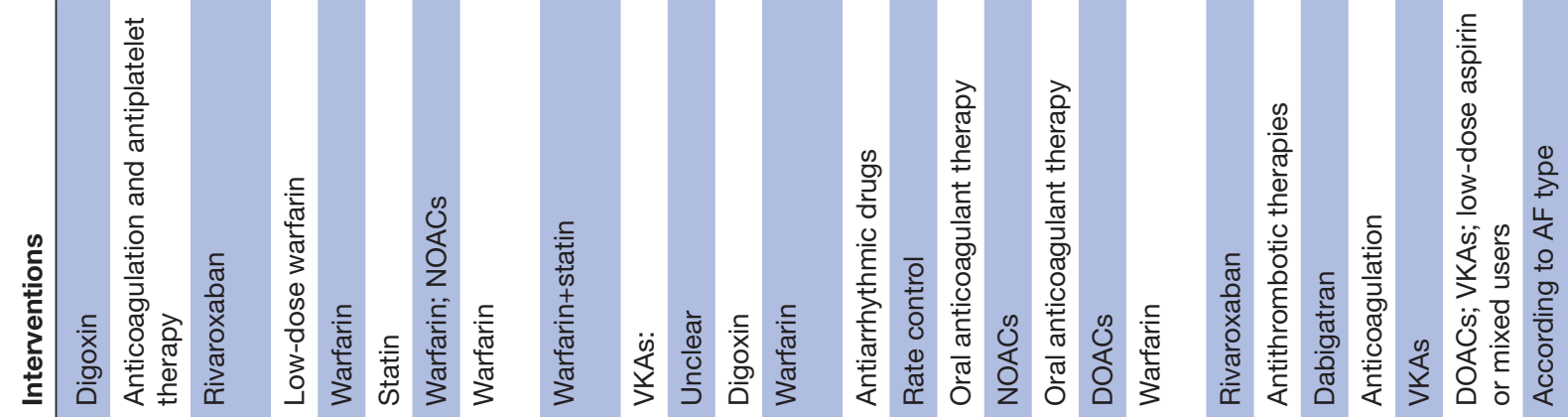

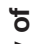

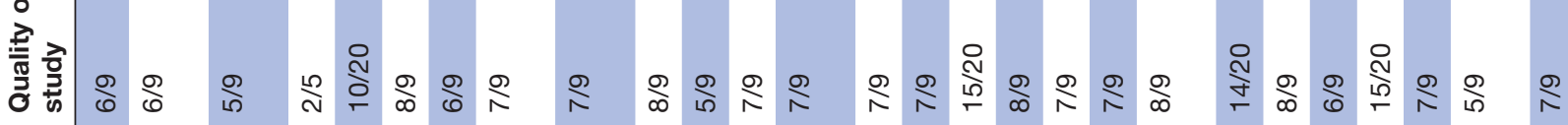

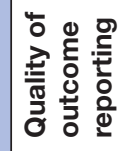

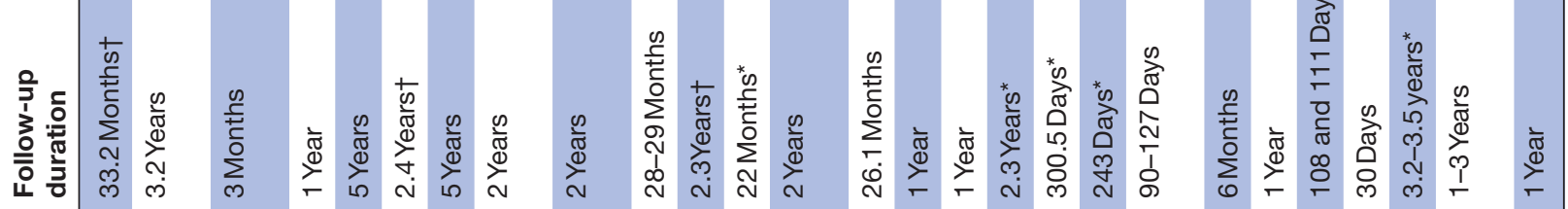

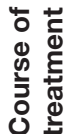

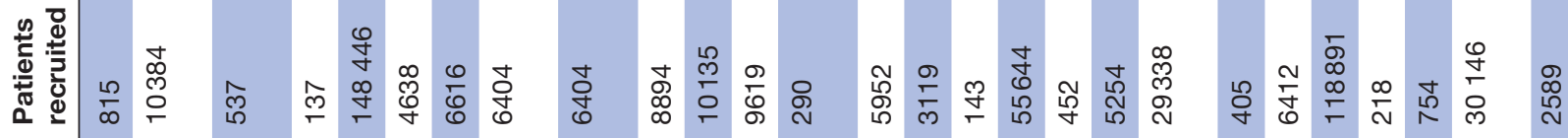

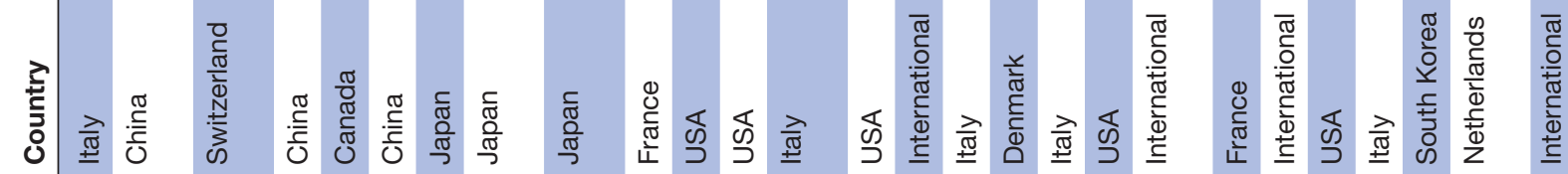
홀

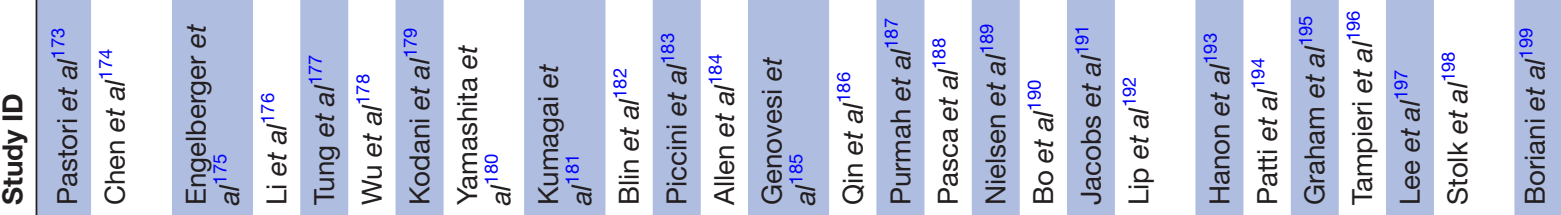




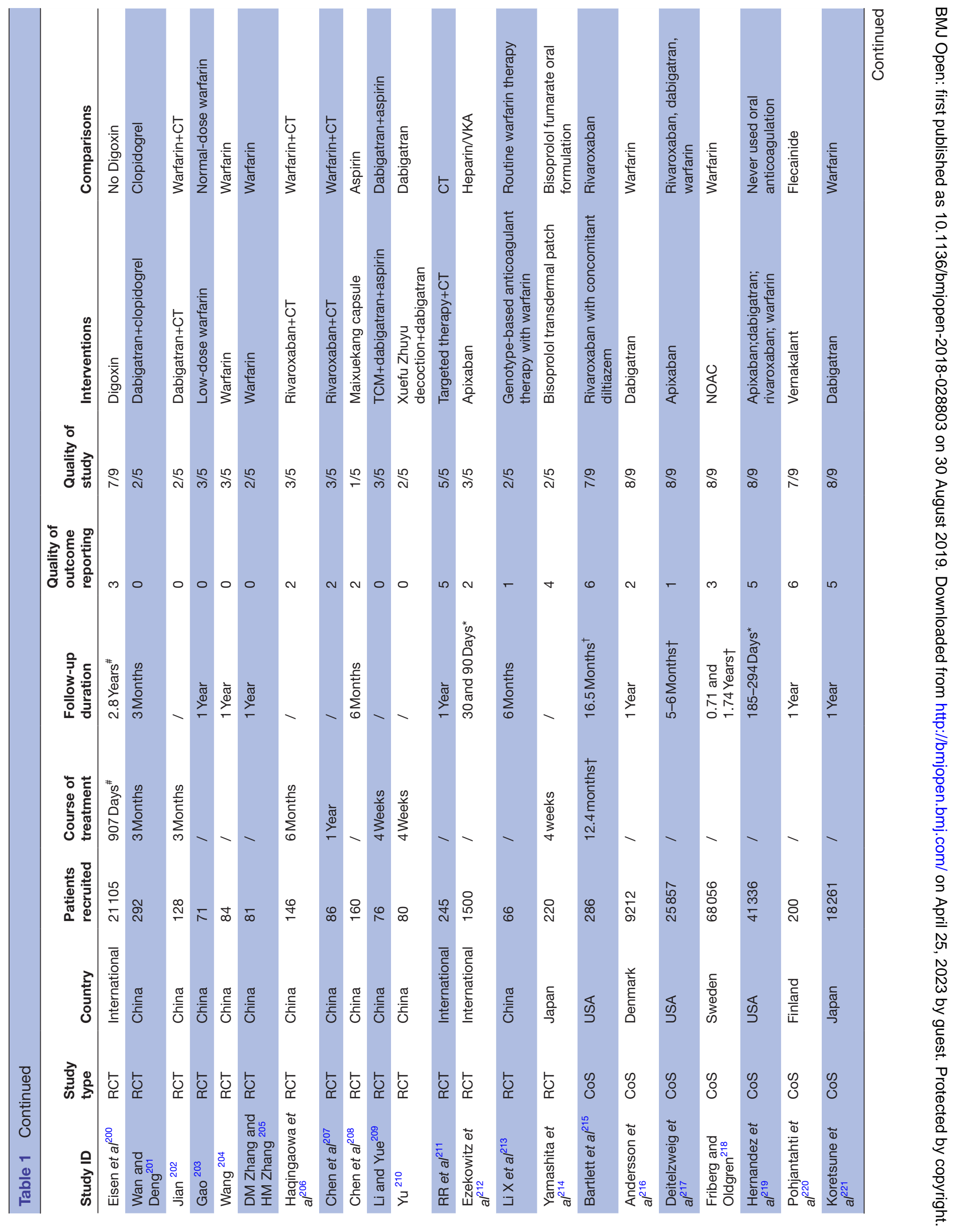




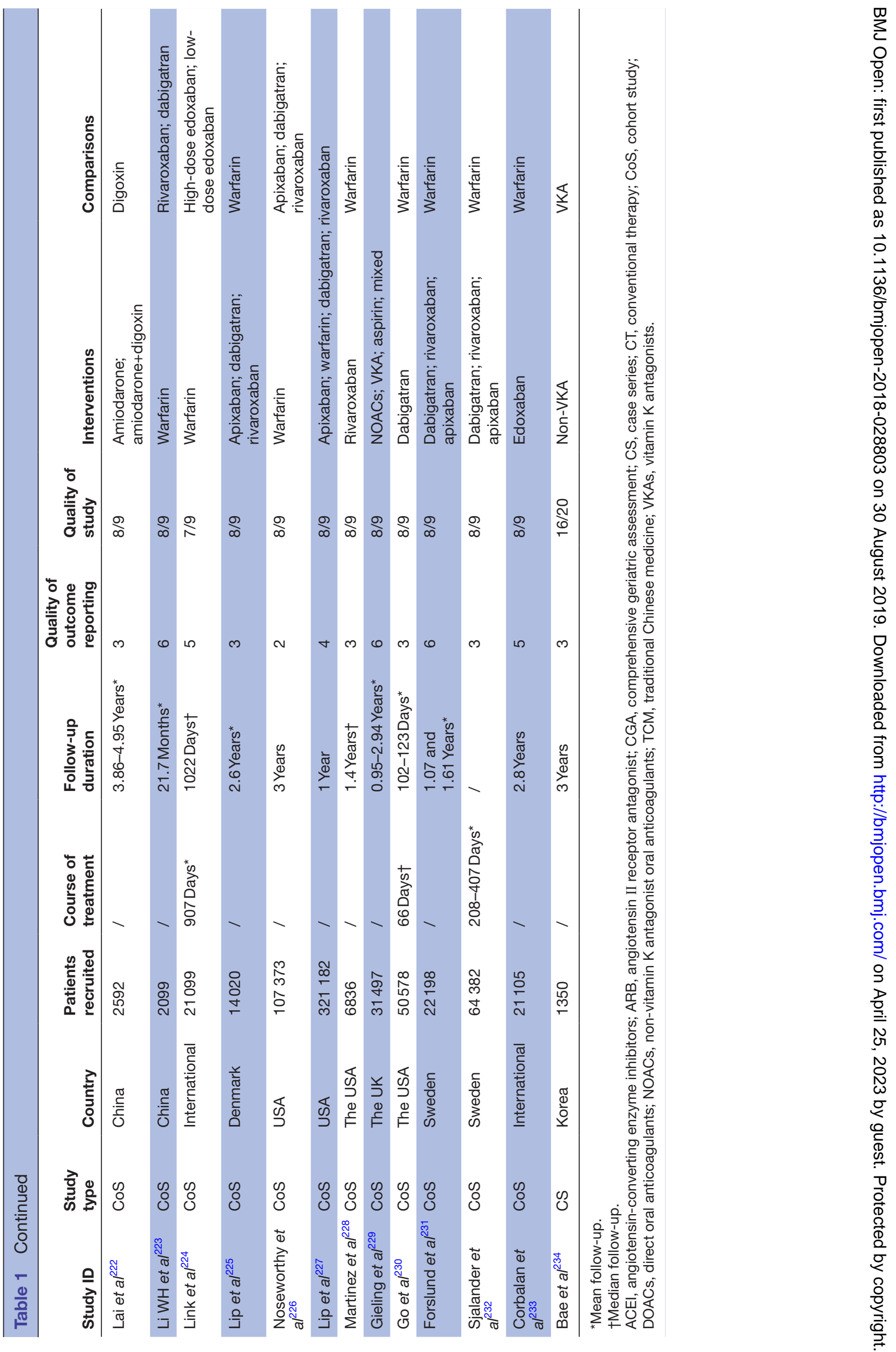




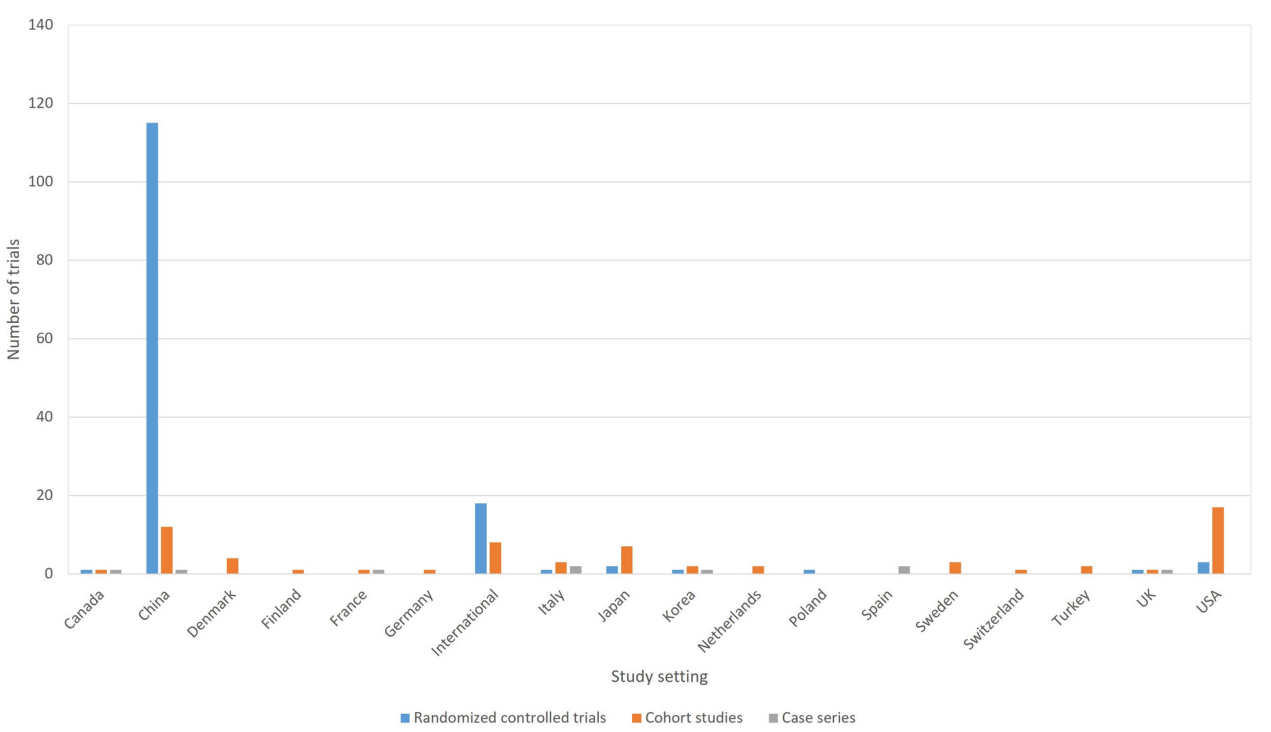

Figure 2 The type and distribution of clinical trials.

in the research or the authors are in the institutions who do not have the ability to conduct RCTs in China.

\section{Study identification}

Two reviewers (RQ and $\mathrm{SH}$ ) independently assessed the titles and abstracts from searches. Then, the full texts of the potential articles were retrieved and assessed for further identification. Any disagreement was resolved by discussion or consulting the third investigator (HS).

\section{Data extraction}

Two reviewers (RQ and $\mathrm{JH}$ ) independently extracted information. The information included the first author's name, publication time, number of participants, country of authors (if the authors are from different countries, it was stated as 'international'), interventions, comparisons, course of treatment, follow-up duration, outcomes, the definition of outcomes, OMIs and measurement time (intervention duration or follow-up time). Any disagreement was resolved by discussion or consulting the third investigator (HS).

In addition, we assessed the quality of outcome reporting according to the method used in other studies. ${ }^{89}$ There were six items; if the information of eligible studies completely meet the items, then 1 point was awarded. If this information did not meet or fully meet the items, then 0 point was awarded. If the outcome was objective, then the definition is unnecessary.

The items include the following:

1. Is the primary outcome clearly stated?

2. Is the primary outcome clearly defined so that another researcher would be able to reproduce its measurement? Where appropriate, this outcome should include a clear description of time points, the person measuring the outcome, how the outcome was measured (for example, tools and methods used) and where the outcome was measured.

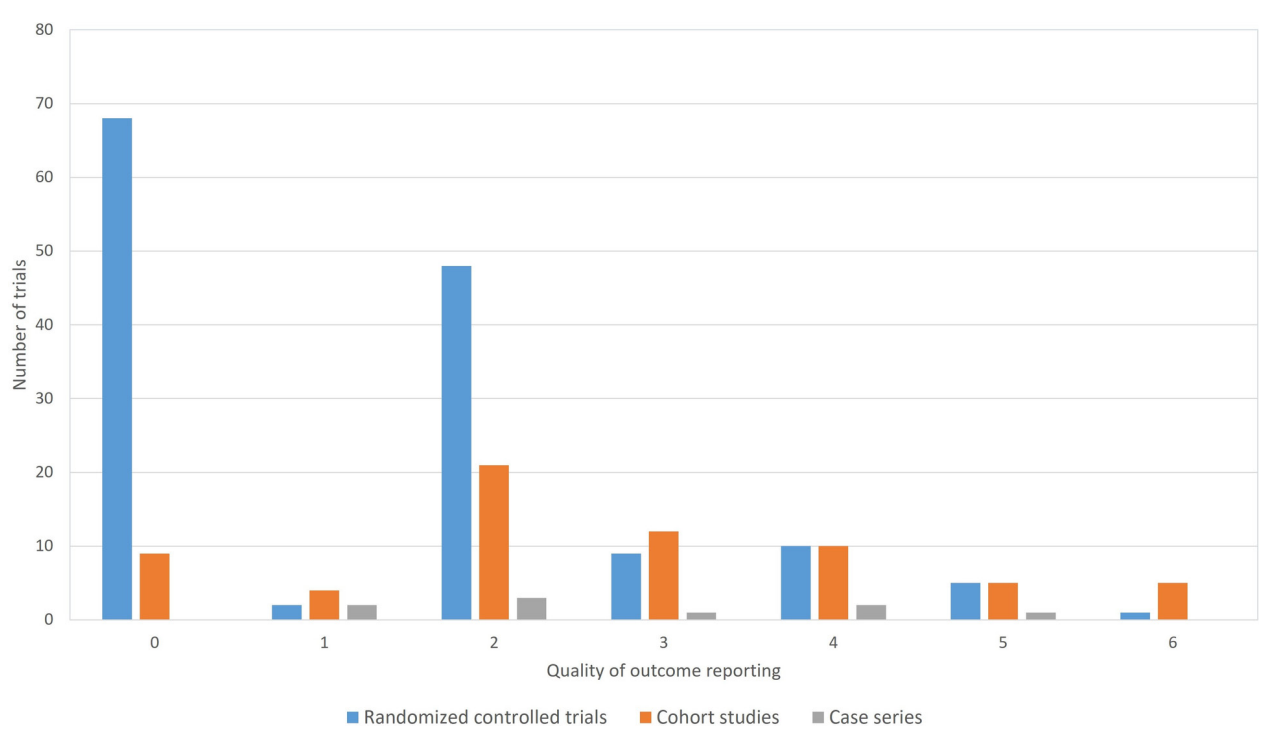

Figure 3 The quality of outcome reporting in different types of clinical trials. 


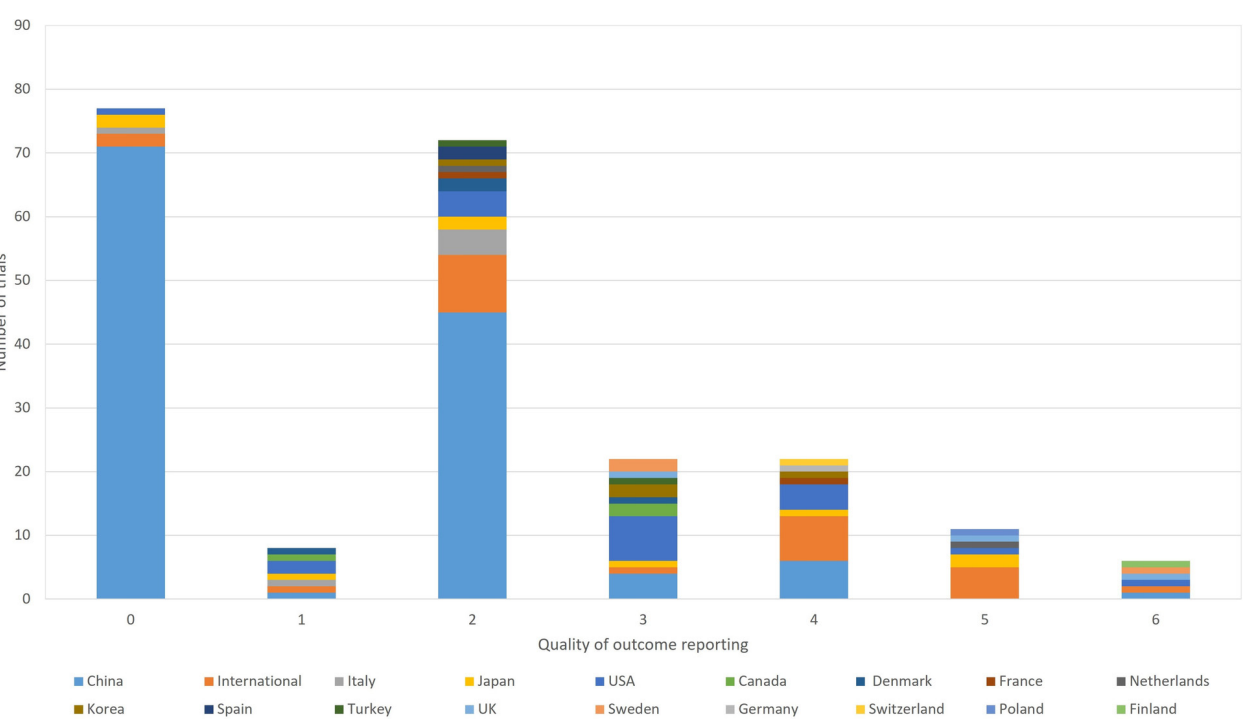

Figure 4 The quality of outcome reporting in different countries.

3. Are the secondary outcomes clearly stated?

4. Are the secondary outcomes clearly defined?

5. Do the authors explain the use of the outcomes they have selected?

6. Are methods used to enhance the quality of outcome measurement (for example, repeated measurement, training) if appropriate?

The methodological quality was assessed according to the type of study. The Jadad score was used to assess the quality of RCTs, ${ }^{10}$ and the Newcastle-Ottawa Scale was used to assess the quality of cohort studies (CoSs). ${ }^{11}$ The tool developed by Canadian Institute of Health Economics can be used to assess the quality of case series studies. ${ }^{12}$

Two reviewers (RQ and $\mathrm{JH}$ ) independently assessed the quality of outcome reporting and the methodological quality. Any disagreement was resolved by discussion or consulting the third investigator (HS).

\section{Merging outcomes and grouping under outcome domains}

Two researchers (RQ and CZ) merged the overlapping outcomes according to the definition of outcomes independently. If no definition was provided, they discussed and achieved consensus if necessary. For example, death, death from any cause, mortality, overall mortality, total mortality, all causes of death and all causes of mortality were aggregated as 'all-cause mortality'.

The original list of outcomes from systematic review is usually very long and unwieldy, ${ }^{13}$ so researchers developed a taxonomy for outcome classification ${ }^{14}$ that included 38 outcome domains. Two researchers (RQ and $\mathrm{CZ)}$ grouped individual outcomes into the appropriate outcome domain together and achieved consensus.

\section{Statistical analysis}

The results were analysed by descriptive analysis.

\section{Patient and public involvement}

Patients and the public were not involved in the design or planning of the study. Patients will be involved in the larger study to develop the COS. Informed consent will be obtained from patients who will participate in the later research.

\section{RESULTS}

\section{Characteristics of literature}

In this systematic review, a total of 25255 articles from Chinese and English databases were retrieved. After removing duplicates, there were 17240 articles. By reading the titles and abstracts, ineligible articles were removed, and full texts for 1233 potential eligible articles were retrieved. A total of 1015 articles were removed for various reasons, and 218 articles were finally included. The flowchart of this systematic review is shown in figure 1 .

In the included studies, 88 studies were for antiarrhythmic therapy, and 130 studies were for anticoagulant therapy. A total of 110 articles were in Chinese, and 108 articles were in English. Thirty articles were TCM clinical trials, and 188 were Western medicine clinical trials. Seventy-five articles were observational studies (including $66 \mathrm{CoS}$ and 9 case series), while 143 articles were RCTs. The general characteristics of the included articles are shown in table 1 .

The majority of RCTs were conducted in China. The USA had more CoSs than other countries did (figure 2). Because of the limited information provided in the articles, $35.32 \%(77 / 218)$ of the studies received 0 points for the quality of outcome reporting, and the majority were RCTs (figure 3). Compared with other countries, China had a much lower quality of outcome reporting (figure 4). The majority of RCTs were poor quality, while the majority of observational studies were high quality.

\section{The list of outcomes}

There are two main types of therapy for NVAF: antiarrhythmic treatment and anticoagulation treatment. Some differences exist in the outcome reporting between these 
Table 2 The outcomes reporting for clinical trials of antiarrhythmic treatment $(\mathrm{N}=88)$

\section{Outcomes OMIs/ \\ reporting definitions Measurement}

Domains/outcomes

(n)

Mortality/survival

$\begin{array}{lrll}\text { All-cause mortality } & 11 & 0 & 8 \\ \begin{array}{l}\text { Cardiovascular } \\ \text { death }\end{array} & 5 & 0 & 3\end{array}$

Vascular outcomes

\begin{tabular}{|c|c|c|c|}
\hline $\begin{array}{l}\text { Non-central } \\
\text { nervous system } \\
\text { embolism }\end{array}$ & 6 & 0 & 2 \\
\hline
\end{tabular}

Cardiac outcomes

\begin{tabular}{|c|c|c|c|}
\hline ECG outcomes & 18 & 2 & 14 \\
\hline Time to conversion & 7 & 1 & 5 \\
\hline $\begin{array}{l}\text { Mean sinus rhythm } \\
\text { maintenance time }\end{array}$ & 1 & 1 & 6 \\
\hline $\begin{array}{l}\text { Time to first AF } \\
\text { recurrence }\end{array}$ & 4 & 1 & 3 \\
\hline $\begin{array}{l}\text { Conversion to sinus } \\
\text { rhythm }\end{array}$ & 26 & 1 & 12 \\
\hline $\begin{array}{l}\text { Sinus rhythm } \\
\text { maintenance }\end{array}$ & 15 & 3 & 6 \\
\hline AF recurrence & 36 & 2 & 2 \\
\hline AF progression & 6 & 2 & 3 \\
\hline AF controlling rate & 2 & 0 & 2 \\
\hline AF persistence & 11 & 2 & 5 \\
\hline $\begin{array}{l}\text { Number of } \\
\text { electrical } \\
\text { cardioversion }\end{array}$ & 1 & 0 & 1 \\
\hline $\begin{array}{l}\text { Number of taking } \\
\text { antiarrhythmic }\end{array}$ & 1 & 0 & 1 \\
\hline
\end{tabular}

drugs

\begin{tabular}{lccc}
$\begin{array}{l}\text { Number of } \\
\text { undertaking } \\
\text { ablation }\end{array}$ & 1 & 0 & 1 \\
$\begin{array}{l}\text { Ultrasonic } \\
\text { cardiogram }\end{array}$ & 39 & 1 & 10 \\
$\begin{array}{l}\text { Heart rate } \\
\text { NYHA classification }\end{array}$ & 21 & 2 & 14 \\
$\begin{array}{l}\text { grading of cardiac } \\
\text { function }\end{array}$ & 3 & 1 & 2 \\
$\begin{array}{l}\text { Myocardial } \\
\text { infarction }\end{array}$ & 2 & 0 & 2 \\
$\begin{array}{l}\text { Bradycardia } \\
\text { Ventricular } \\
\text { arrhythmia }\end{array}$ & 1 & 0 & 0 \\
\hline $\begin{array}{l}\text { Heart failure } \\
\text { Blood pressure }\end{array}$ & 2 & 1 & 1 \\
\hline NT-proBNP & 3 & 0 & 2 \\
\hline Blood and lymphatic system outcomes & 6 \\
\hline D-dimer & 2 & 0 & 2 \\
\hline APTT & 1 & 0 & 1 \\
\hline
\end{tabular}

Continued
Table 2 Continued

\section{Outcomes OMIs/}

reporting definitions Measurement

$\begin{array}{llll}\text { Domains/outcomes (n) } & \text { (n) time point (n) }\end{array}$

$\begin{array}{llll}\text { TT } & 1 & 0 & 1 \\ \text { PT } & 1 & 0 & 1 \\ \text { FIB } & 3 & 1 & 3\end{array}$

Nervous system outcomes

$\begin{array}{lccc}\begin{array}{l}\text { Haemorrhagic } \\ \text { stroke }\end{array} & 11 & 0 & 6 \\ \text { Ischaemic stroke } & 6 & 0 & 4 \\ \text { Immune system outcomes } & & \end{array}$

Immune system outcomes

\begin{tabular}{lrrl}
\hline IFN- $\gamma$ & 1 & 0 & 1 \\
\hline IL-10 & 1 & 0 & 1 \\
\hline IL-4 & 1 & 0 & 1 \\
IL-6 & 10 & 1 & 4 \\
\hline TNF- $\alpha$ & 9 & 1 & 4 \\
\hline MMP2 & 4 & 1 & 3 \\
\hline Solubility P-selectin & 1 & 1 & 1 \\
\hline $\begin{array}{l}\text { Connective tissue } \\
\text { growth factor }\end{array}$ & 1 & 1 & 1 \\
\hline
\end{tabular}

$\begin{array}{llll}\text { TIMP2 } & 1 & 1 & 1\end{array}$

Endocrine outcomes

\begin{tabular}{llll} 
Aldosterone & 1 & 0 & 1 \\
\hline ANP & 1 & 1 & 1 \\
\hline TSH & 2 & 0 & 1 \\
\hline Renin, Angll & 4 & 1 & 1 \\
\hline Adiponectin & 1 & 1 & 1
\end{tabular}

Hepatobiliary outcomes

$\begin{array}{llll}\text { ALT } & 1 & 0 & 3 \\ \text { AST } & 1 & 0 & 3\end{array}$

Renal and urinary outcomes

$\begin{array}{llll}\text { BUN } & 6 & 1 & 3 \\ \text { Serum creatinine } & 1 & 0 & 3 \\ \text { Urine sodium } & 1 & 0 & 1\end{array}$

Metabolism and nutrition outcomes

\begin{tabular}{llll} 
HDL-C & 3 & 0 & 4 \\
\hline LDL-C & 7 & 1 & 4 \\
TC & 6 & 0 & 4 \\
TG & 5 & 0 & 4 \\
\hline Serum & 3 & 1 & 3
\end{tabular}

$$
\text { homocysteine }
$$

General outcomes

\begin{tabular}{lrll}
$\begin{array}{l}\text { Body mass index } \\
\begin{array}{l}\text { Mean drug onset } \\
\text { time }\end{array}\end{array}$ & 1 & 0 & 1 \\
Symptoms & 9 & 2 & 7 \\
CRP & 6 & 1 & 5 \\
hs-CRP & 12 & 2 & 4 \\
\hline
\end{tabular}

Continued 
Table 2 Continued

\begin{tabular}{|c|c|c|c|}
\hline Domains/outcomes & $\begin{array}{l}\text { Outcomes } \\
\text { reporting } \\
\text { (n) }\end{array}$ & $\begin{array}{l}\text { OMls/ } \\
\text { definitions } \\
\text { (n) }\end{array}$ & $\begin{array}{l}\text { Measurement } \\
\text { time point }(n)\end{array}$ \\
\hline \multicolumn{4}{|l|}{ Adherence/compliance } \\
\hline $\begin{array}{l}\text { Therapeutic } \\
\text { compliance }\end{array}$ & 1 & 0 & 5 \\
\hline \multicolumn{4}{|c|}{ Withdrawal from treatment } \\
\hline $\begin{array}{l}\text { Withdrawal from } \\
\text { treatment }\end{array}$ & 1 & 0 & 1 \\
\hline \multicolumn{4}{|l|}{ Physical functioning } \\
\hline 6 Min walk test & 1 & 1 & 1 \\
\hline \multicolumn{4}{|l|}{ Adverse events/effects } \\
\hline $\begin{array}{l}\text { Adverse events/ } \\
\text { side effects }\end{array}$ & 26 & 0 & 8 \\
\hline \multicolumn{4}{|l|}{ Resource use: Hospital } \\
\hline $\begin{array}{l}\text { All-cause } \\
\text { hospitalisation }\end{array}$ & 5 & 0 & 3 \\
\hline $\begin{array}{l}\text { Cardiovascular } \\
\text { hospitalisations }\end{array}$ & 6 & 1 & 4 \\
\hline $\begin{array}{l}\text { Hospital length of } \\
\text { stay }\end{array}$ & 1 & 0 & 0 \\
\hline Readmission rates & 1 & 0 & 1 \\
\hline
\end{tabular}

ALT, alanine aminotransferase; ANP, atrial natriuretic peptide;APTT, activated partial thromboplastin time; AST, aspartate aminotransferase; BUN, blood urea nitrogen; CRP, $C$ reactive protein; ECG, electrocardiogram; FIB, fibrinogen; HDL-C, High density lipoprotein cholesterol; IFN- $\gamma$, interferon- $\gamma$; IL, interleukin; LDL-C, low-density lipoprotein cholesterol; MMP2, matrix metalloproteinase-2; NT-proBNP, N terminal pro B type natriuretic peptide; NYHA, New York Heart Association; $\mathrm{PT}$, prothrombin time; TC, total cholesterol; TG, total triglyceride; TIMP2, tissue inhibitor of metalloproteinase 2; TNF- $\alpha$, tumour necrosis factor- $\alpha$; TSH, thyroid stimulating hormone; TT, thrombin time.

therapies. This review shows the outcomes according to the type of interventions in the original study.

For clinical trials of antiarrhythmic therapy, 69 outcomes from 16 outcome domains were reported (table 2). Twenty-eight $(31.82 \%, 28 / 88)$ outcomes were reported only once; the most frequently reported outcome was ultrasonic cardiogram, which was reported 39 times $(44.32 \%$, $39 / 88$ ). None of the outcomes were reported more than 50 times. In the 16 outcome domains, 5 outcome domains (vascular outcomes, adherence/compliance, adverse events/effects; physical functioning; withdrawal from treatment) consisted of only one outcome. These outcomes were reported between 1 and 26 times, and the median outcome reporting time was 1. Cardiac outcomes consisted of the largest number of outcomes, including 22 outcomes. In cardiac outcomes, ultrasonic cardiogram (39 times), AF recurrence (36 times), conversion to sinus rhythm (26 times), heart rate (21 times) and blood pressure (20 times) were reported much more often than other outcomes.
Table 3 The outcomes reporting for clinical trials of anticoagulant treatment $(\mathrm{N}=130)$

\begin{tabular}{|c|c|c|c|}
\hline Domains/outcomes & $\begin{array}{l}\text { Outcomes } \\
\text { reporting } \\
\text { (n) }\end{array}$ & $\begin{array}{l}\text { OMls/ } \\
\text { definitions (n) }\end{array}$ & $\begin{array}{l}\text { Measurement } \\
\text { time point (n) }\end{array}$ \\
\hline \multicolumn{4}{|l|}{ Mortality/survival } \\
\hline All-cause mortality & 52 & 2 & 40 \\
\hline $\begin{array}{l}\text { Cardiovascular } \\
\text { death }\end{array}$ & 26 & 2 & 13 \\
\hline $\begin{array}{l}\text { Death from } \\
\text { ischaemic events }\end{array}$ & 3 & 0 & 1 \\
\hline Death from stroke & 1 & 1 & 1 \\
\hline Death from bleeding & 1 & 0 & 1 \\
\hline $\begin{array}{l}\text { Non-cardiovascular } \\
\text { death }\end{array}$ & 1 & 0 & 1 \\
\hline \multicolumn{4}{|l|}{ Vascular outcomes } \\
\hline $\begin{array}{l}\text { Non-central nervous } \\
\text { system embolism }\end{array}$ & 73 & 1 & 31 \\
\hline Major bleeding & 75 & 10 & 42 \\
\hline $\begin{array}{l}\text { Time to first major } \\
\text { bleeding event }\end{array}$ & 2 & 0 & 3 \\
\hline Minor bleeding & 21 & 2 & 8 \\
\hline $\begin{array}{l}\text { Clinically relevant } \\
\text { non-major bleeding }\end{array}$ & 15 & 4 & 5 \\
\hline $\begin{array}{l}\text { Time to first } \\
\text { clinically relevant } \\
\text { non-major bleeding } \\
\text { event }\end{array}$ & 1 & 0 & 2 \\
\hline Time to the first SEE & 2 & 0 & 1 \\
\hline \multicolumn{4}{|l|}{ Cardiac outcomes } \\
\hline $\begin{array}{l}\text { Acute coronary } \\
\text { syndrome }\end{array}$ & 31 & 0 & 27 \\
\hline $\begin{array}{l}\text { Ultrasonic } \\
\text { cardiogram }\end{array}$ & 1 & 1 & 1 \\
\hline Blood pressure & 1 & 0 & 1 \\
\hline Heart failure & 1 & 0 & 1 \\
\hline NT-proBNP & 2 & 1 & 3 \\
\hline
\end{tabular}

Blood and lymphatic system outcomes

\begin{tabular}{lrll} 
INR & 17 & 1 & 7 \\
Prothrombin time & 8 & 1 & 5 \\
APTT & 8 & 1 & 5 \\
PT & 10 & 2 & 6 \\
TT & 5 & 1 & 5 \\
FIB & 4 & 1 & 3 \\
Thrombin time & 5 & 1 & 4 \\
Time spent in the & 5 & 0 & 3 \\
therapeutic range & & & \\
PLT & 2 & 0 & 2 \\
RBC & 1 & 0 & 1 \\
HGB & 1 & 0 & 1 \\
D-dimer & 3 & 0 & 3 \\
Haemorheology & 1 & 1 & 1 \\
Thromboela- & 1 & 1 & 1 \\
stogram & & & \\
\hline
\end{tabular}

Continued 


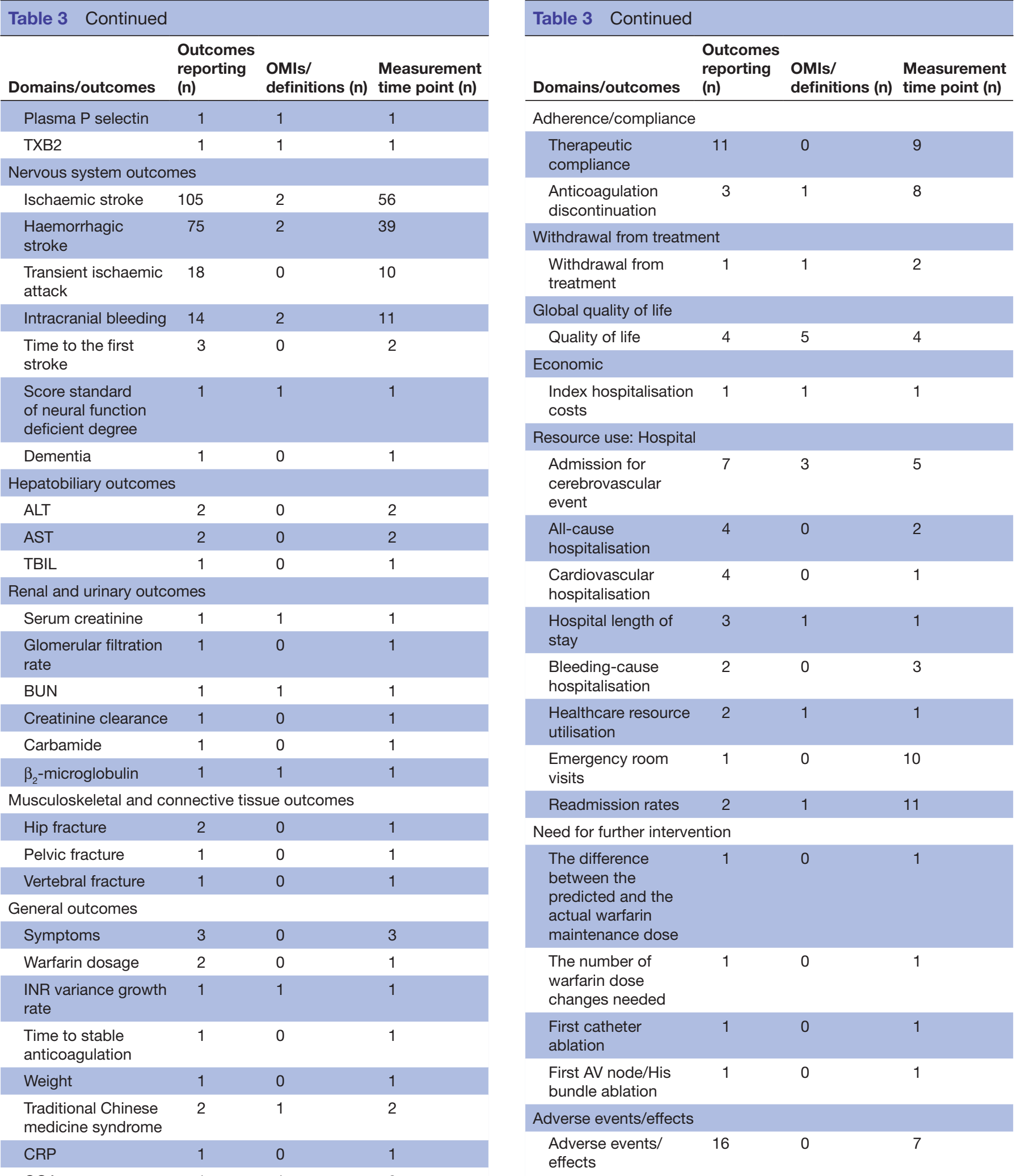

$\begin{array}{llll}\text { CGA score } & 1 & 1 & 2\end{array}$

\begin{tabular}{llll}
$\begin{array}{l}\text { Physical functioning } \\
\text { Modified Rankin }\end{array}$ & 1 & 1 & 1 \\
$\begin{array}{l}\text { Scale score } \\
\text { Disability }\end{array}$ & 1 & 0 & 1 \\
$\begin{array}{l}\text { Satisfaction/patient preference } \\
\text { Patient satisfaction }\end{array}$ & 3 & 3 & 4 \\
\hline
\end{tabular}

ALT, alanine aminotransferase; APTT, activated partial thromboplastin time; AST, aspartate aminotransferase; AV, atrioventricular; BUN, blood urea nitrogen; CGA, comprehensive geriatric assessment; CRP, $C$ reactive protein; FIB, fibrinogen; $H G B$, haemoglobin; INR, international normalised ratio; NT-proBNP, N terminal pro B type natriuretic peptide; PLT, platelet; PT, prothrombin time; RBC, red blood cell; SEE, systemic embolic event; TBIL, total bilirubin; TT, thrombin time; TXB2, thromboxane B2. 


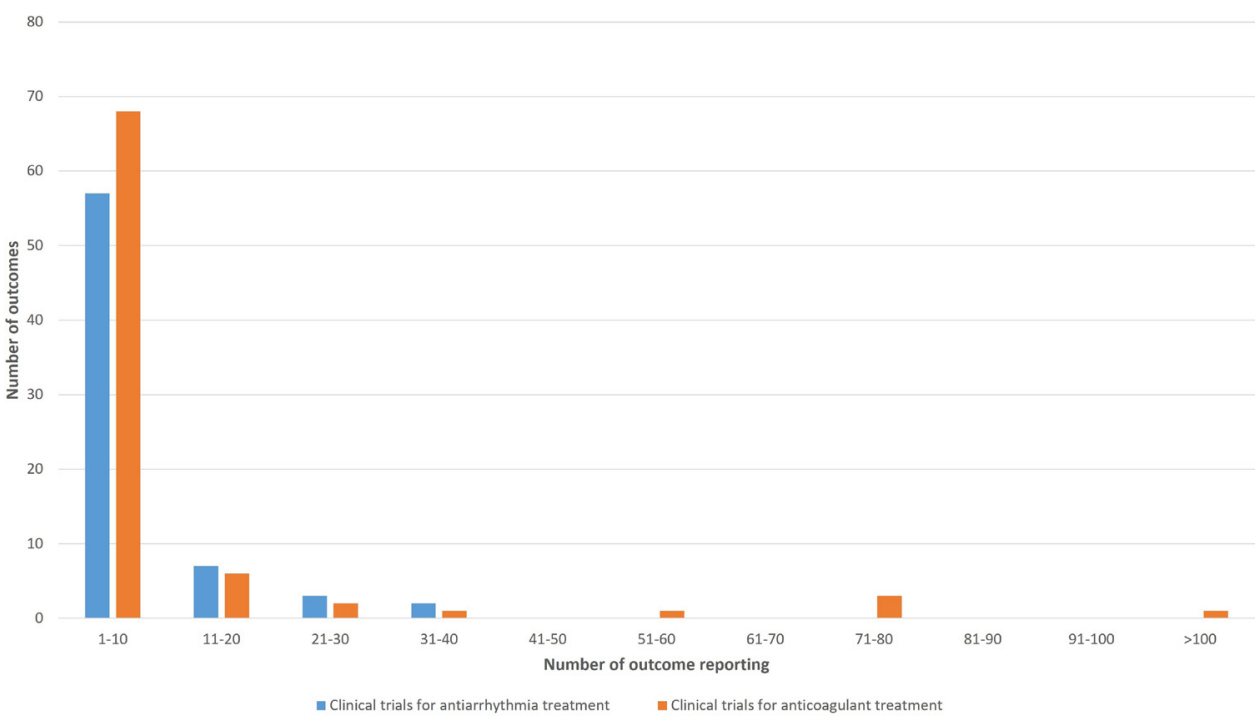

Figure 5 The summary of outcome reporting times.

For clinical trials of anticoagulation therapy, there were 82 outcomes from 18 outcome domains in the studies of anticoagulation therapy (table 3$)$. Thirty-eight (29.23\%, $38 / 130$ ) outcomes were reported only once; the most frequently reported outcome was ischaemic stroke, which was reported 105 times $(80.77 \%, 105 / 130)$. Only $5(3.85 \%$, $5 / 130$ ) outcomes were reported more than 50 times. In the 18 outcome domains of anticoagulation therapy studies, 5 outcome domains (satisfaction/patient preference, withdrawal from treatment, global quality of life, economic and adverse events/effects) consisted of only one outcome. These outcomes were reported between 1 and 16 times, and the median outcome reporting time was 3. Blood and lymphatic system outcomes included the largest number of outcomes, which was 14 outcomes; the international normalised ratio (INR) was reported more frequently than other outcomes.

There were 24 duplicated outcomes between antiarrhythmic therapy and anticoagulation therapy. After removing duplicates, there were 127 outcomes. Figure 5 shows a summary of outcomes reporting times. Figure 6 shows the number of outcomes in different outcome domains in antiarrhythmic treatment trials. Figure 7 shows the number of outcomes in different outcome domains in anticoagulation treatment trials.

A large number of clinical trials did not provide definitions or OMIs. In the outcomes of antiarrhythmic treatment trials, 31 outcomes $(44.93 \%, 31 / 69)$ were provided definitions or OMIs. Twenty-three $(33.33 \%, 23 / 69)$ outcomes were provided one OMI or definition, seven $(10.14 \%, 7 / 69)$ outcomes were provided two OMIs or definitions and one $(1.45 \%, 1 / 69)$ outcome was provided three OMIs or definitions. Sinus rhythm maintenance had three different OMIs or definitions, which was higher than that of other outcomes. In the outcomes of anticoagulant therapy trials, $40(48.78 \%, 40 / 82)$ were provided OMIs or definitions. Twenty-eight $(35.37 \%, 28 / 82)$ outcomes were provided one OMI or definition, seven $(8.54 \%, 7 / 82)$ outcomes were provided two OMIs or definitions and five $(6.10 \%, 5 / 82)$ outcomes were provided

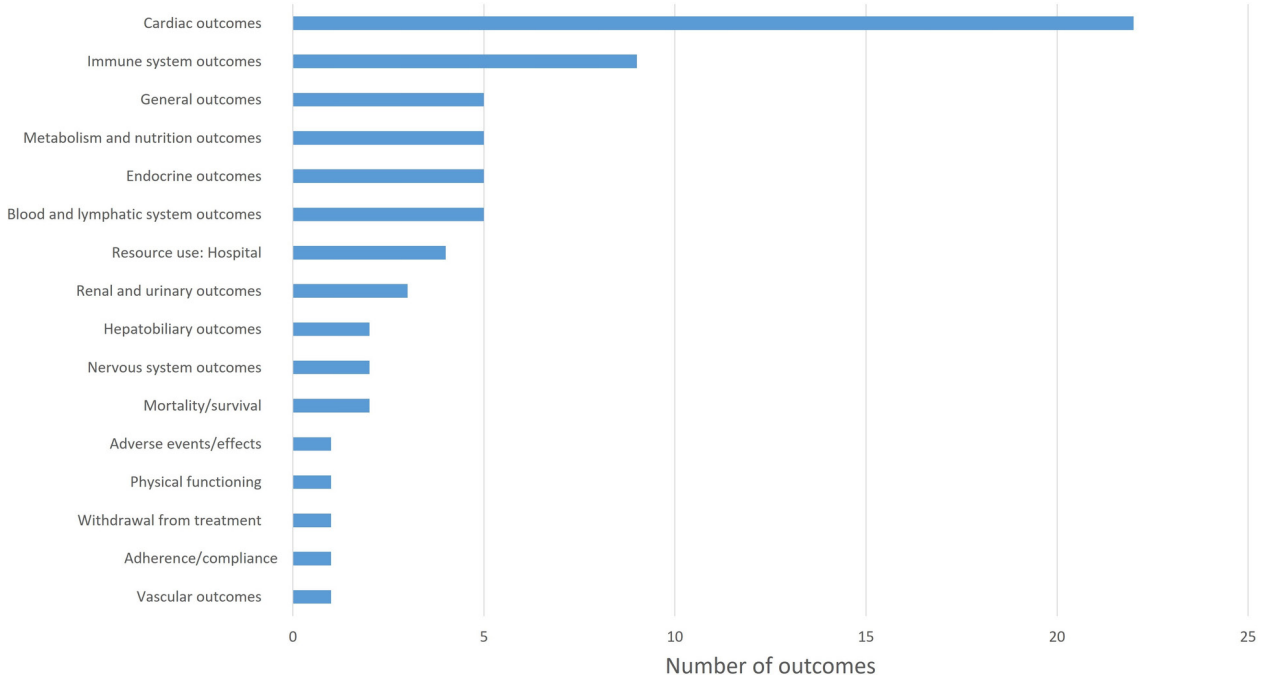

Figure 6 The number of outcomes in different outcome domains in antiarrhythmic treatment trials. 


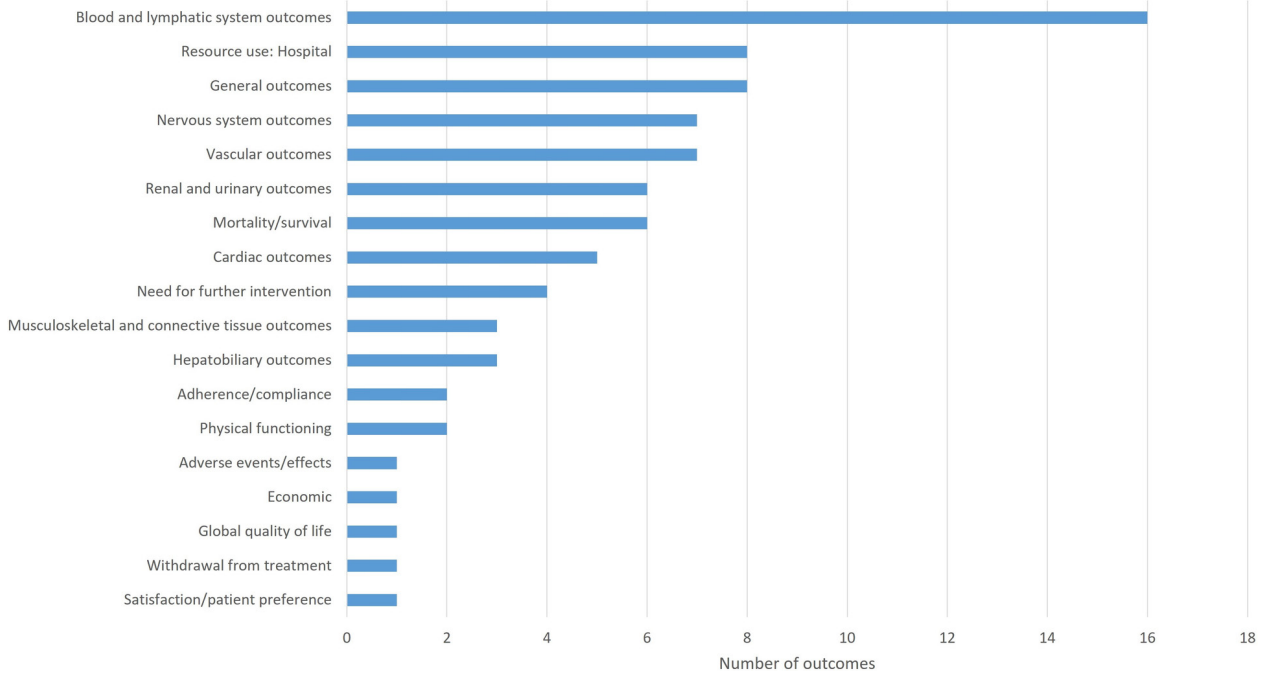

Figure 7 The number of outcomes in different outcome domains in anticoagulant treatment trials.

three or more OMIs or definitions. Major bleeding had more definitions than other outcomes did.

In addition, there were many different measurement times for the same outcome. In the clinical trials of antiarrhythmic treatment, the outcome measurement times ranged from 1 to -14 times, and the median time was 3.Forty-three outcomes $(62.32 \%, 43 / 69)$ had two or more measurement times. Heart rate and ECG outcomes had more measurement times than other outcomes did. In clinical trials of anticoagulant therapy, the outcome measurement times ranged from 1 to 56 , with a median of 1.5; among these outcomes $41(50.00 \%, 41 / 82)$ had two or more measurement times. In addition, ischaemic stroke had more measurement times than other outcomes did.

\section{DISCUSSION}

This systematic review is the first to evaluate the quality of outcome reporting of clinical trials of TCM and western medicine for treating NVAF. The results showed variations in the outcome reporting, OMIs/outcome definitions and outcome measurement time reporting in different clinical trials. These problems may result in the exclusion of some studies from systematic reviews/meta-analyses due to the heterogeneity of outcomes or outcome measurements; thus, these studies cannot provide a higher level of evidence for clinical practice.

In clinical trials for NVAF, investment wastes also exist because approximately $1 / 3$ of outcomes were reported only once in included trials of anticoagulation therapy and antiarrhythmic therapy. For example, conversion to sinus rhythm, which is important to the results of clinical trials of antiarrhythmic therapy, was reported by $29.55 \%$ $(26 / 88)$ of articles. Some long-term outcomes, such as all-cause mortality and cardiovascular deaths, were reported in $12.50 \%(11 / 88)$ and $5.68 \%(5 / 88)$ of articles, respectively.

In addition, adverse events/effects were inadequately reported. In clinical trials of anticoagulant therapy, safety outcomes such as haemorrhage were grouped under vascular outcomes according to the degree of bleeding (such as major bleeding, clinically relevant non-major bleeding and minor bleeding). Then, only $12.31 \%$ $(16 / 130)$ of the included articles reported other kinds of adverse events/effects. For clinical trials of antiarrhythmic therapy, only $29.55 \%(26 / 88)$ of the included articles reported adverse events/effects.

For all of the outcomes in the list, patient' perspectives could not be identified sufficiently. For example, among all of the included 88 articles for antiarrhythmic therapy, none of them reported quality of life, while in all of the included 130 articles for anticoagulant therapy, only 4 of them reported quality of life.

There were 30 articles for clinical trials of TCM. TCM syndrome, which could reflect the characteristics of TCM, was reported only two times. A few other articles reported symptoms related to TCM syndrome. This phenomenon cannot reflect the characteristics and advantages of TCM.

After assessing the quality of outcome reporting and studies, the results showed that the majority of included trials had poor quality. Although the poor quality of studies may not influence the result of developing a long list of outcomes, the poor quality of outcome reporting made it difficult to extract sufficient information from the articles. The reasons for poor quality of studies and outcome reporting may be because most studies in China do not follow the Consolidated Standards of Reporting Trials (CONSORT) statement or observational studies reporting items. Moreover, the majority of journals in Chinese do not require studies to follow the CONSORT statement; thus, some studies provided limited information on key methodological issues. In addition, Chinese researchers prefer to report comprehensive outcomes rather than individual outcomes, and studies have reported only primary outcomes.

Only a small number of included studies provided OMIs or definitions, which made it difficult to assess 
the quality of outcome measures. Additionally, the variation in OMIs or definitions can make it impossible to conduct meta-analyses. In addition, selecting OMIs with good measurement properties is very important after developing a $\operatorname{COS}^{15}$ to ensure that reliability, validity and ethical standards are achieved.

The measurement time was much shorter in Chinese journals than in English journals. In general, long-term outcomes were usually reported in observational studies, while short-term outcomes were usually reported in RCTs. It is a challenge for a single trial to measure all of these outcomes in a meaningful way, especially an outcome such as mortality, which requires longer follow-up and a larger sample size. ${ }^{16}$ Therefore, recommending measurement times for different outcomes is important.

Developing a COS for NVAF may reduce the heterogeneity of outcome reporting in different clinical trials, so that clinical trials can be included in systematic reviews/ meta-analyses to provide a higher quality of evidence for clinical practice. Moreover, if the majority of clinical trials can be included in systematic review, it may help reduce investment wastes. Reviewers can easily determine if publication bias is present when a COS is used. For TCM clinical trials, a COS may help improve the quality of studies if researchers report consensus outcomes, which may help improve the development of TCM.

\section{Author affiliations \\ ${ }^{1}$ Key Laboratory of Chinese Internal Medicine of Ministry of Education and Beijing, Dongzhimen Hospital, Beijing University of Chinese Medicine, Beijing, China ${ }^{2}$ Baokang Affiliated Hospital of Tianjin University of Traditional Chinese Medicine, Tianjin, China \\ ${ }^{3}$ Evidence-based Medicine Center, Jiangxi University of Chinese Medicine, Nanchang, China}

Contributors $\mathrm{RQ}, \mathrm{JC}$ and $\mathrm{HS}$ contributed to the study design. $\mathrm{RQ}$ extracted data from articles and drafted the manuscript. SH, YH, TH, CZ and JH contributed to the data extracting and assessment. ML, JH, JC, YL, MG and HS revised the manuscript. All authors read and approved the final manuscript.

Funding This work was supported by the National Natural Science Foundation of China [81430098].

Competing interests None declared.

Patient consent for publication Not required.

Ethics approval Ethical approval has been granted by the Ethics Committee of Dongzhimen Hospital, Beijing University of Chinese Medicine (DZMEC-KY-2017-81).

Provenance and peer review Not commissioned; externally peer reviewed.

Data availability statement The data are from published papers and do not include identifiable patient data.

Open access This is an open access article distributed in accordance with the Creative Commons Attribution Non Commercial (CC BY-NC 4.0) license, which permits others to distribute, remix, adapt, build upon this work non-commercially, and license their derivative works on different terms, provided the original work is properly cited, appropriate credit is given, any changes made indicated, and the use is non-commercial. See: http://creativecommons.org/licenses/by-nc/4.0/.

\section{REFERENCES}

1. Odutayo A, Wong CX, Hsiao AJ, et al. Atrial fibrillation and risks of cardiovascular disease, renal disease, and death: systematic review and meta-analysis. BMJ 2016;354.
2. January CT, Wann LS, Alpert JS, et al. 2014 AHA/ACC/HRS guideline for the management of patients with atrial fibrillation: a report of the American College of Cardiology/American heart association Task force on practice guidelines and the heart rhythm Society. J Am Coll Cardiol 2014;64:e1-76.

3. Kirchhof P, Benussi S, Kotecha D, et al. 2016 ESC guidelines for the management of atrial fibrillation developed in collaboration with EACTS. Rev Esp Cardiol 2017;70.

4. Heart Rhythm Society of the Chinese Society of Biomedical Engineering, Nao Xin Tong Zhi Committee of the Chinese Association of Integrative Medicine. Expert consensus on Wenxin granule for treatment of cardiac arrhythmias. Chin Med $J$ 2017;130:203-10.

5. COMET Initiative. Available: http://www.comet-initiative.org/ [Accessed 1 Apr 2019].

6. Shang H, Qiu R, Zhang X, et al. A core outcome set for clinical trials of traditional Chinese medicine in non-valvular atrial fibrillation. Available: http://www.comet-initiative.org/studies/details/941 [Accessed 1 Apr 2019].

7. Qiu R, Li M, Zhang X, et al. Development of a core outcome set (COS) and selecting outcome measurement instruments (OMls) for non-valvular atrial fibrillation in traditional Chinese medicine clinical trials: study protocol. Trials 2018;19:541.

8. Durnea CM, Pergialiotis V, Duffy JMN, et al. A systematic review of outcome and outcome-measure reporting in randomised trials evaluating surgical interventions for anterior-compartment vaginal prolapse: a call to action to develop a core outcome set. Int Urogynecol J 2018;29:1727-45.

9. Alkhaffaf B, Blazeby JM, Williamson PR, et al. Reporting of outcomes in gastric cancer surgery trials: a systematic review. BMJ Open 2018;8:e21796.

10. Jadad AR, Moore RA, Carroll D, et al. Assessing the quality of reports of randomized clinical trials: is blinding necessary? Control Clin Trials 1996;17:1-12.

11. Wells G, Shea B, O'Connell D, et al. The Newcastle-Ottawa scale (NOS) for assessing the quality of nonrandomised studies in meta-analyses. Available: http://www.ohri.ca/programs/clinical_ epidemiology/oxford.as $p$ [Accessed 1 Apr 2019].

12. Moga C, Guo B, Schopflocher D. Development of a quality appraisal tool for case series studies using a modified Delphi technique. Edmonton AB: Institute of Health Economics, 2012. https://www. ine.ca/research-programs/rmd/cssqac/cssqac-info [Accessed 1 Apr 2019].

13. Hopkins JC, Howes N, Chalmers K, et al. Outcome reporting in bariatric surgery: an in-depth analysis to inform the development of a core outcome set, the BARIACT study. Obes Rev 2015;16:88-106.

14. Dodd S, Clarke M, Becker L, et al. A taxonomy has been developed for outcomes in medical research to help improve knowledge discovery. J Clin Epidemiol 2018;96:84-92.

15. Prinsen CAC, Vohra S, Rose MR, et al. How to select outcome measurement instruments for outcomes included in a "Core Outcome Set" - a practical guideline. Trials 2016;17:449.

16. Marcum ZA, Steinman MA. Developing a core outcome set for trials to improve medication use: guidelines or guidance? J Am Geriatr Soc 2018;66:1058-9.

17. Kang DW. Antithrombotic therapy for coronary heart disease complicated with atrial fibrillation [In Chinese]. Gansu Med J 2015;34:118-20.

18. Guo SG, Guo JR, Xu HL, et al. Effect of atorvastatin on the prognosis in patients with coronary heart disease complicated with chronic heart failure and atrial fibrillation [In Chinese]. Hainan Med J 2015;26:486-9.

19. Li L, Luo XL, Wang HY. Analysis on efficacy and safety of amiodarone combined with dabigatran etexilate in treatment of non-valvular atrial fi-brillation [In Chinese]. Lab Med Clin 2015;12:1997-8.

20. Bu QF, Jiao DL, LiFX. Effectivity and safety of low-intensity warfarin anticoagulation in elderly patients with nonvascular atrial fibrillation [In Chinese]. Clin J Med Off 2015;43:969-70.

21. Pan XM, Liu S. Effects of candesartan and rosuvastatin on the left atrial structure of patients with atrial fibrillation [In Chinese]. Chinese Baby 2016;9:11-12.

22. Li D. Effect of dabigatran on coagulation function in elderly patients with non-valvular atrial fibrillation [In Chinese]. Shandong Med J 2015;55:65-6.

23. Chen J, Hong HS, Zhou YW. Study on Application of Warfarin in Treatment of Non Valvular Atrial Fibrillation Anticoagulation [In Chinese]. China Contin Med Educ 2015;7:117-9.

24. Sang J, Sui LJ, Gao CZ. Effects of valsartan combined with rosuvastatin on plasma levels of $\mathrm{C}$-reactive protein, tumor necrosis factor- $\alpha$ and interleukin- 6 in elderly patients with 
permanent atrial fibrillation [In Chinese]. Chin $\mathrm{J}$ Gerontol 2015;35:2025-7.

25. Guo LP. Efficacy of amiodarone combined with irbesartan in the prevention of atrial fibrillation. Chin Pract Med 2015;10:152-3.

26. Zuo J, Gao Y, Hua Y, et al. Evaluation on the efficacy and safety of pradaxa on non - valvular atrial fibrillation anticoagulation therapy in 90 cases [In Chinese]. China Pharmaceuticals 2015;24:42-3.

27. Liu YH, Li HY, Zhang SL, et al. Clinical observation of dabigatran etexilate in anticoagulant therapy for non-valvular atrial fibrillation [In Chinese]. Cardiovasc Dis J Int Tradit Chin Western Med 2016;4:3-4.

28. Yang D. Therapeutic effect of amlodipine on patients with hypertension complicated with atrial fibrillation [In Chinese]. For All Health 2015;9:145-6.

29. Li HW, Li J, Tao J. Clinical observation of patients with hypertension combined with persistent atrial fibrillation in the treatment of candesartan combined with amiodarone [In Chinese]. Med Inform 2015;28:30-1.

30. Yang XB, Wang MY, Zhang YJ, et al. Clinical observation of sotalol combined with irbesartan in patients with hypertension complicated with paroxysmal atrial fibrillation [In Chinese]. Chin J Prim Med Pharm 2015;22:123-4

31. Li GH, Lai YW, Yang YP. Clinical trial of effect of valsartan on inflammatory factors in patients with hypertension complicated with persistent atrial fibrillation [In Chinese]. Chin J Mod Drug Appl 2015;9:89-90.

32. Lin W, Yu DH, Li ZY. Therapeutic effect of rosuvastatin on elderly patients with chronic heart failure complicated with atrial fibrillation [In Chinese]. Chin J Mod Drug App/ 2015;9:127-8.

33. Qin PY, Xuan CX, Zhou Q. Therapeutic effect of proper doses of warfarin on prevention of ischemic stroke in patients of different ages with non-valvular atrial fibrillation [In Chinese]. J Guangxi Med Univ 2016;33:691-3.

34. Qin PY, Zhou Q, Xuan CX. Observation of efficiency and safety of different dosages of warfarin in prevention of thromboembolism in young and middle-aged patients with nonvalvular atrial fibrillation [In Chinese]. Psychol Doct 2016;22:30-1.

35. Chen $\mathrm{L}, \mathrm{Xu} J$, Ren $\mathrm{Q}$, et al. The curative effect observation of dabigatran etexilate combined with dual antiplatelet for antithrombotic therapy after percutaneous coronary intervention of non-valvular atrial fibrillation for atrial fibrillation [In Chinese]. Shaanxi Med J 2016;45:758-9.

36. Wang WM, Peng BT, Chen J, et al. The effect of anti-platelet and anticoagulant therapy on preventing ischemic stroke in patients with non-valvular atrial fibrillation [In Chinese]. Chin J Mod Drug Appl 2015;9:169-71.

37. Liu JX, Zhang X. Effect of different dosage of warfarin on the incidence of hemorrhage and D-dimer concentration in patients with non-valvular atrial fibrillation [In Chinese]. Cardiovasc Dis J Int Tradit Chin West Med 2015;3:85-6.

38. Zhang RH. Clinical efficacy and safety evaluation of irbesartan in the treatment of atrial fibrillation [In Chinese]. Contemp Med $2015 ; 21: 124-5$

39. Zhang YT. Clinical observation of amiodarone in treatment of acute myocardial infarction complicated with atrial fibrillation [In Chinese] China \& Foreign Med Treat 2015;14:101-2.

40. Huang ZX, Xie CL, He ZW. Clinical study on irbesartan combined ammonia amiodarone in treatment of non-valvular paroxysmal atrial fibrillation [In Chinese]. Med Innov China 2015;12:57-9.

41. Xu X, Wang B, Chen S. Clinical observation of antithrombotic effect of warfarin and aspirin in elderly patients with paroxysmal atrial fibrillation [In Chinese]. Chin J Int Med Cardio Cerebrovasc Dis 2015;13:118-9

42. Lin X. Clinical efficacy of candesartan combined with amiodarone in the treatment of elderly patients with hypertension complicated with persistent atrial fibrillation [In Chinese]. Chin J Gerontol 2015;35:6754-6.

43. Zhang Z, Zong YQ. The effect of different dosage of warfarin in treatment of elderly patients with stable coronary heart disease and combined atrial fibrillation. Cardiovascular Disease [In Chinese]. J Int Tradit Chin West Med2016;4:1-2.

44. Guo WD. Clinical efficacy of amiodarone combined with irbesartan in the treatment of paroxysmal atrial fibrillation [In Chinese]. Chin J Clin Ration Drug Use 2015;8:31-2.

45. Zhang JS. Clinical efficacy and safety of valsartan and indapamide in the treatment of paroxysmal atrial fibrillation [In Chinese]. J Med Forum 2015;36:158-9.

46. Yang ZQ, Yao XL. Efficacy Obs ervation of Bisoprolol with Methimazole Treatment of Elderly Patients with Subclinical Hyperthyroidism and Atrial Fibrillation [In Chinese]. Mod Diagn Treat 2015;26:801-2.
47. Zhang RS, Gu X. Efficiency of intravenous amiodarone in congestive heart failure patients with atrial fibrillation [In Chinese]. Chin J Mult Organ Dis Elder 2015;14:454-7.

48. Hou L, Liu MY. Clinical observation of amiodarone combined with irbesartan in the treatment of 136 patients with paroxysmal atrial fibrillation [In Chinese]. Psychol Doct 2015;21:50-1.

49. Jiang YC, Xu B. Effect of amiodarone plus valsartan treatment in senile patients With persistent atrial fibrillation [In Chinese]. Tianjin Pharm 2016;28:28-30.

50. Song CY, Lv LF, Zhong Y. Effect of amiodarone combined with fosinopril on the efficacy of electrocardiogram in patients with atrial fibrillation [In Chinese]. World Latest Med Inform 2015;15.

51. Wang Q, Yuan W. Evaluation of the therapeutic effect of bisoprolol on heart failure patients with persistent atrial fibrillation [In Chinese] Med Inform 2015;28:26-7.

52. Yan HF, Huang XY, Cai JF. Treatment of elderly patients with AMI and $\mathrm{AF}$ by Propafenone and Amiodarone and analysis the efficacy and adverse reactions [In Chinese]. J China Prescription Drug 2015;13:12-13.

53. Zhang Y, Yin SN. Clinical efficacy of amiodarone combined with irbesartan in the treatment of patients with hypertension complicated with paroxysmal atrial fibrillation. Chin J Integr Med Cardio Cerebrovasc Dis 2015;13:534-5.

54. Jian JQ. The efficacy and safety of warfarin in the treatment of atrial fibrillation [In Chinese]. Health Guide 2017;16.

55. Huang HW, Qin XX. Clinical observation of dabigatran etexilate in prophylactic anticoagulation of elderly nonvalvular atrial fibrillation: 30 cases [In Chinese]. J Guangdong Med Coll 2016;34:282-4.

56. Yang HX. Effect of rosuvastatin on hypertension and paroxysmal atrial fibrillation [In Chinese]. Psychol Doct 2017;23:7-8.

57. Liu XB, Huang HM, Feng LL, et al. Different intensity warfarin anticoagulation therapy for elderly stable coronary heart disease patients with atrial fibrillation [In Chinese]. Chin J Geriat Heart Brain Vessel Dis 2016;18:132-5.

58. Zhou L, Tang L, Xing X, et al. Effects of different doses of atorvastatin on high-sensitivity C-reactive protein, interleukin-6, tumor necrosis factor- $\alpha$, adiponectin levels in elderly patients with coronary heart disease complicated with atrial fibrillation [In Chinese]. Chin J Gerontol 2016;36:2892-3.

59. Chen J. Clinic Effects of Amiodarone combining enalapril in treatment of patients with hypertension and paroxysmal atrial fibrillation [In Chinese]. Med Recapitulate 2016;22:1812-5.

60. Wang XM, Jin L. Effect of strengthen rosuvastatin in the treatment of patients with paroxysmal atrial fibrillation in coronary artery disease and the influence on serum inflammatory factor [In Chinese]. Chin J Prim Med Pharm 2016;23:961-4.

61. Ou Y. Application effect and mechanism analysis of atorvastatin in the treatment of elderly patients with coronary heart disease and atrial fibrillation [In Chinese]. Chin Commun Doct 2017:33:17-18.

62. Geng QF, Liu YH, Li HY, et al. The efficacy of aspirin combined with dipyridamole in patients with non-valvular atrial fibrillation [In Chinese]. Cardiovasc Dis J Integr Tradit Chin West Med 2016;4:1-2.

63. Chu YZ. Clinical efficacy and safety of amiodarone and benazepril in the treatment of paroxysmal atrial fibrillation [In Chinese]. Chin $J$ Pract Med 2017;44:18-20.

64. Zhu Y. Efficacy of candesartan combined with amiodarone in elderly patients with hypertension complicated with persistent atrial fibrillation [In Chinese]. Chin J Med Device 2017;30:17-18.

65. Lin S. Efficacy of telmisartan combined with amiodarone in the patients with hypertension complicated with paroxysmal atrial fibrillation and influence on the levels of serum BNP, MMP-2 and CTGF [In Chinese]. China Pharm 2017;20:1055-8.

66. Duan WT, Shi D, Wang XD, et al. The effect of maintaining sinus rhythm of amiodarone combined in patients with persistent atrial fibrillation [In Chinese]. Chin J Gerontol 2017;37:1924-5.

67. Lu Y, Wen LA, Li D, et al. Clinical observation of dabigatran and warfarin in treating nonvalvular atrial fibrillation [In Chinese]. China Pharm 2017;26:49-51.

68. Wei ZY, Lin YP. Compared the efficacy and safety of dabigatran with warfarin in the treatment of atrial fibrillation complicated with chronic kidney disease. Chin Prev Med 2016;17:947-50.

69. Su Q, Cheng J, Deng XF, et al. Clinical study of amiodarone in the treatment of elderly patients with acute myocardial infarction complicated with atrial fibrillation [In Chinese]. Prog Mod Biomed 2017:17:856-8.

70. Yu HY. The efficacy of amiodarone combined with irbesartan in patients with hypertension complicated with paroxysmal atrial fibrillation [In Chinese]. Med J Chin People Health 2016;28:27-8.

71. Li XY, Huang J, Dai J. The efficacy of perindopril combined with atorvastatin on inflammatory factors in patients with hypertension 
complicated with paroxysmal atrial fibrillation [In Chinese]. Jiangsu Med J 2016;42:2720-2.

72. Wen H. Clinical study of different doses of aspirin in preventing thrombosis in patients with atrial fibrillation [In Chinese]. Heilongjiang Med Pharm 2016;39:57-8.

73. Chen YL. Antithrombotic effect of different doses of warfarin in elderly patients with paroxysmal atrial fibrillation [In Chinese]. $J$ Bethune Mil Med Coll 2016;14:71-2.

74. Xu ZT, Feng ZX, Wang Q, et al. Compared the therapeutic effect of metoprolol combined with spironolactone with metoprolo combined with valsartan in the treatment of isolated paroxysmal atrial fibrillation [In Chinese]. Prev Treat Cardio Cerebral Vasc Dis 2016;16:48-50.

75. Huang $\mathrm{H}, \mathrm{He} \mathrm{XQ}$, Zhang $\mathrm{HM}$, et al. Effects of rosuvastatin on hypertension with paroxysmal atrial fibrillation [In Chinese]. J Trop Med 2016;16:1132-6.

76. Zhao TB, Dong XH. Effect of atorvastatin calcium on elderly patients with chronic heart failure complicated with atrial fibrillation [In Chinese]. China Prescription Drug 2017;15.

77. Feng WJ, Zhang R, Li LL, et al. Therapeutic effect and safety of combined therapy of Maixuekang capsule and low-intensityanticoagulation warfarin with aspirin on acute cerebral infarction in elderly patients with non-valvular atrial fibrillation [In Chinese] Hebei Med J 2015;37:663-5.

78. Bo YL, Li WZ, Pan XM. Clinical observation of the effect of amiodarone combined with wenxin granules on conversion and maintenance of sinus rhythm in 80 patients with atrial fibrillation [In Chinese]. Chin J Ethnomed Ethnopharm 2015;24:53-4.

79. Zhang BG, Peng ZX. Clinical observation of buyanghuanwu decoction in treatment of chronic heart failure with rapid atria fibrillation [In Chinese]. Hubei J Tradit Chin Med 2016;38:1-3.

80. Chen YY, Yan ZQ, He XP, et al. Effect of Jianxin Pinglu Pill on MMP 2 and TIMP 2 in patients with persistent atrial fibrillation [In Chinese]. Chin J Integr Med Cardio Cerebrovasc Dis 2016;14:1194-6.

81. Cao WZ, Zhong DC, Shi ZY, et al. Clinical efficacy and influence of Shensongyangxin capsule on inflammatory factors in patients with atrial fibrillation [In Chinese]. Chin J Diff Complicat Cases 2015;14:387-90.

82. Chang GD, Zhou YT. Clinical observation of atorvastatin combined with wenxin granules in the treatment of paroxysmal atrial fibrillation [In Chinese. Med Innov China 2015;12:63-4.

83. Fan XJ. Efficacy of losartan combined with amiodarone and Shensong Yangxin capsule in the treatment of hypertension with paroxysmal atrial fibrillation [In Chinese]. For All Health 2015;9.

84. Ye LJ Clinical observation of the therapeutic effect of Wenxin granule combined with propafenone in patients with atrial fibrillation [In Chinese]. Cardiovas Dis J Integr Tradit Chin West Med 2016;4:68-9.

85. Wang TX. To observe the curative effect of Taoren Honghua decoction combined with warfarin in the treatment of non valvular atrial ifbrillation and blood stasis [In Chinese]. Cardiovas Dis J Integr Tradit Chin West Med 2015;3:30-2.

86. Cheng J, Zhang DC, Fan LL, et al. Clinical Reaserch of Yangxin Guicao Tang in Patients with Persistent or Permanent Atrial Fibrillation [In Chinese]. Liaon J Tradit Chin Med 2015;42:1254-6.

87. Han J, Deng Y, Chen JC, et al. The efficacy of Xifeng Zhizhi Decoction in treating 30 patients with paroxysmal atrial fibrillation [In Chinese]. Glob Tradit Chin Med 2015;8:602-4.

88. Peng XG. Effect of Shexiang Baoxin pills combined with amiodarone on heart rate, blood pressure and atrial fibrillation in patients with hypertensive heart disease complicated with atrial fibrillation [In Chinese]. J New Chin Med 2015;47:16-17.

89. Zhang ML. Effect of Buchang Wenxin Granule in the treatment of elderly patients with diastolic heart failure and paroxysmal atrial fibrillation [In Chinese]. Chin J Pract Med 2015;42:69-70.

90. Pan TS, Yan ZQ, Chen YY, et al. Clinical observation of Jianxin Pinglu pill combined with amiodarone in the treatment of paroxysmal atrial fibrillation[In Chinese]. J New Chin Med 2016;48:14-15

91. Huang SS. Clinical efficacy of valsartan combined with Dabuyuanjian on elderly patients with paroxysmal atrial fibrillation [In Chinese]. Clin Med 2016;36:11-12.

92. Li FN, Kuang P, Chen Y, et al. Effect of Shensongyangxin capsules combined with amiodarone on MMP-2 and hs-CRP of patients with paroxysmal atrial fibrillation [In Chinese]. Intern Med China 2016;11:694-7.

93. Wang LN, Wang XF. Effect of the Wenxin granules on inflammatory cytokines of patients with permanent atrial fibrillation [In Chinese]. Chin J Pract Med 2016;43:123-5.
94. Cui XT. Effect of Zhigancao decoction combined with metoprolol on ventricular rate and plasma Hcy level in patients with chronic atrial fibrillation [In Chinese]. Mod J Integr Tradit Chin West Med 2017;26:162-3.

95. Bi MH. Effect of Dingxin granule on early blood pressure in patients with hypertension complicated with paroxysmal atrial fibrillation [In Chinese]. Chin Foreign Med Res 2016;14:110-1.

96. Zhang XS. Efficacy observation of sotalol combined with shensong yangxin capsule in the treatment of coronary heart disease with rapid atrial fibrillation [In Chinese]. Med Innov China 2017;14:99-102.

97. Chen T, Chang ZL, Fan XH, et al. Effect of Zhigancao decoction combined with amiodarone on paroxysmal atrial fibrillation and atrial remodeling [In Chinese]. China Mod Doct 2017;55:118-21.

98. Liu J, Liao Y, Tang Y. Effect of Dingxin granules combined with metoprolol on $\mathrm{P}$ wave dispersion and serum inflammatory factors in patients with paroxysmal atrial fibrillation [In Chinese]. Mod J Integr Tradit Chin West Med 2017;26:2564-6.

99. Zhang RZ. Curative effect observation of Wenxin Granule combined with amiodarone in treating 84 cases of paroxysmal atrial fibrillation [In Chinese]. Clin J Chin Med 2016;8:37-8.

100. Granger CB, Lopes RD, Hanna M, et al. Clinical events after transitioning from apixaban versus warfarin to warfarin at the end of the apixaban for reduction in stroke and other thromboembolic events in atrial fibrillation (ARISTOTLE) trial. Am Heart $J$ 2015;169:25-30.

101. Held C, Hylek EM, Alexander JH, et al. Clinical outcomes and management associated with major bleeding in patients with atrial fibrillation treated with apixaban or warfarin: insights from the ARISTOTLE trial. Eur Heart J 2015;36:1264-72.

102. Jaspers Focks J, Brouwer MA, Wojdyla DM, et al. Polypharmacy and effects of apixaban versus warfarin in patients with atrial fibrillation: post hoc analysis of the ARISTOTLE trial. BMJ 2016;353.

103. Bahit MC, Lopes RD, Wojdyla DM, et al. Non-major bleeding with apixaban versus warfarin in patients with atrial fibrillation. Heart 2017:103:623-8.

104. Alexander $\mathrm{JH}$, Andersson U, Lopes RD, et al. Apixaban $5 \mathrm{Mg}$ twice daily and clinical outcomes in patients with atrial fibrillation and advanced age, low body weight, or high creatinine: a secondary analysis of a randomized clinical trial. JAMA Cardiol 2016;1:673-81.

105. Hu PT, Lopes RD, Stevens SR, et al. Efficacy and safety of apixaban compared with warfarin in patients with atrial fibrillation and peripheral artery disease: insights from the ARISTOTLE trial. J Am Heart Assoc 2017;6:e004699.

106. Pengo V, Zambon C-F, Fogar P, et al. A randomized trial of pharmacogenetic warfarin dosing in naïve patients with NonValvular atrial fibrillation. PLOS One 2015;10:e0145318.

107. Steffel J, Giugliano RP, Braunwald E, et al. Edoxaban vs. warfarin in patients with atrial fibrillation on amiodarone: a subgroup analysis of the engage AF-TIMI 48 trial. Eur Heart J 2015;36:2239-45.

108. Yamashita T, Koretsune $Y$, Yang $Y$, et al. Edoxaban vs. Warfarin in East Asian patients with atrial fibrillation- An ENGAGE AF-TIMI 48 subanalysis. Circ J 2016;80:860-9.

109. Kato ET, Giugliano RP, Ruff CT, et al. Efficacy and safety of edoxaban in elderly patients with atrial fibrillation in the engage AFTIMI 48 trial. J Am Heart Assoc 2016;5:e003432.

110. Meng Z, Tan J, He Q, et al. Wenxin keli versus sotalol for paroxysmal atrial fibrillation caused by hyperthyroidism: a prospective, open label, and randomized study. Evid Based Complement Altern Med 2015;2015:1-9.

111. Wang H, Zhou X-K, Zheng L-F, et al. Comparison of aspirin and Naoxintong capsule 0 with adjusted-dose warfarin in elderly patients with high-risk of non-valvular atrial fibrillation and genetic variants of vitamin $\mathrm{K}$ epoxide reductase. Chin J Integr Med 2018;24:247-53.

112. Brambatti $\mathrm{M}$, Darius $\mathrm{H}$, Oldgren J, et al. Comparison of dabigatran versus warfarin in diabetic patients with atrial fibrillation: results from the RE-LY trial. Int J Cardiol 2015;196:127-31.

113. Verdecchia P, Reboldi G, Angeli F, et al. Dabigatran vs. warfarin in relation to the presence of left ventricular hypertrophy in patients with atrial fibrillation- the randomized evaluation of long-term anticoagulation therapY (RE-LY) study. Europace 2018;20:253-62.

114. Tan Q, Zhang S, Zou X, et al. Fluvastatin therapy could not decrease progression of paroxysmal atrial fibrillation in non-valvular disease patients. Anatol J Cardiol 2017:18:103-7.

115. Shah R, Hellkamp A, Lokhnygina $Y$, et al. Use of concomitant aspirin in patients with atrial fibrillation: findings from the rocket $A F$ trial. Am Heart J 2016;179:77-86.

116. Sun Y, Hu D, Stevens S, et al. Efficacy and safety of rivaroxaban versus warfarin in patients from mainland China with nonvalvular 
atrial fibrillation: a subgroup analysis from the rocket $A F$ trial. Thromb Res 2017;156:184-90.

117. Yao H, Jiang L, Lin $X$, et al. Fluvastatin combined with benazepril may contribute to the favorable prognosis of patients with atrial fibrillation. Biomed Pharmacother 2016;83:687-92.

118. Goette A, Merino JL, Ezekowitz MD, et al. Edoxaban versus enoxaparin-warfarin in patients undergoing cardioversion of atrial fibrillation (ENSURE-AF): a randomised, open-label, phase 3B trial. Lancet 2016;388:1995-2003.

119. Magnani G, Giugliano RP, Ruff CT, et al. Efficacy and safety of edoxaban compared with warfarin in patients with atrial fibrillation and heart failure: insights from engage AF-TIMI 48. Eur $\mathrm{J}$ Heart Fail 2016;18:1153-61.

120. Senoo K, Lip GYH, Lane DA, et al. Residual risk of stroke and death in anticoagulated patients according to the type of atrial fibrillation. Stroke 2015;46:2523-8.

121. Hijazi Z, Hohnloser SH, Andersson U, et al. Efficacy and safety of apixaban compared with warfarin in patients with atrial fibrillation in relation to renal function over time. JAMA Cardiol 2016;1:451-60.

122. Cadrin-Tourigny J, Shohoudi A, Roy D, et al. Decreased mortality with beta-blockers in patients with heart failure and coexisting atria fibrillation an AF-CHF substudy. JACC Heart Fail 2017;5:99-106.

123. Maciag A, Farkowski MM, Chwyczko T, et al. Efficacy and safety of antazoline in the rapid cardioversion of paroxysmal atrial fibrillation (the AnPAF study). Europace 2017:19:1637-42.

124. $\mathrm{Ng} \mathrm{KH}$, Shestakovska O, Connolly SJ, et al. Efficacy and safety of apixaban compared with aspirin in the elderly: a subgroup analysis from the AVERROES trial. Age Ageing 2016;45:77-83.

125. Inoue $\mathrm{H}$, Atarashi $\mathrm{H}$, Okumura $\mathrm{K}$, et al. Heart rate control by carvedilol in Japanese patients with chronic atrial fibrillation: the AF carvedilol study. J Cardiol 2017;69:293-301.

126. Dong Z, Yao H, Miao Z, et al. Pretreatment with intravenous amiodarone improves the efficacy of ibutilide treatment on cardioversion rate and maintenance time of sinus rhythm in patients with persistent atrial fibrillation. Biomed Rep 2017;6:686-90.

127. Hong K-S, Kwon SU, Lee SH, et al. Rivaroxaban vs warfarin sodium in the ultra-early period after atrial fibrillation-related mild ischemic stroke: a randomized clinical trial. JAMA Neurol 2017;74:1206-15.

128. Tan Q, Li GP, Zhang SY, et al. Effect of fluvastatin on preventing the recurrence of paroxysmal atrial fibrillation [In Chinese]. J Chin Pract Diagn Ther 2017;31:384-6.

129. Zhang $Y Q$, Yin XR. Effects of different doses of rosuvastatin in patients with paroxysmal atrial fibrillation [In Chinese]. Pract Geriat 2016;30:994-6.

130. Zhou H, Wang ZJ, Zhou MF, et al. Clinical research of telmisartan in preventing hypertension with paroxysmal atrial fibrillation [In Chinese]. Chin J Prim Med Pharm 2016;23:3696-700.

131. Qian CS, Sun Y, Sheng CH, et al. Clinical observation of Yiqi Yangyin in treating DHF complicated with atrial fibrillation [In Chinese]. Zhejiang Clin Med J 2017;19:662-4.

132. Di Y, Wang ZJ, Zha WH, et al. Effect of telmisartan on recurrence of paroxysmal atrial fibrillation in patients with hypertension and cardiac dysfunction [In Chinese]. J Clin Intern Med 2017;34:316-9.

133. Liu ZY. Clinical efficacy of valsartan in the treatment of hypertension complicated with atrial fibrillation [In Chinese]. Chin J Integr Med Cardio Cerebrovas Dis 2017:15:1374-6.

134. Yu M, Yu AQ, Yu DJ. Influence of rosuvastatin combined with valsartan in $C$ reactive protein and myocardium remodeling in patients with hypertension complicated with paroxysmal atrial fibrillation [In Chinese]. Chin J Lab Diagn 2017;21:1141-4.

135. Zhang J, Jiao WW. Research advances of new oral anticoagulants in the prevention of stroke in patients with non-valvular atrial fibrillation [In Chinese]. J Int Neurol Neurosurg 2015;42:538-41.

136. Li J, Zhou Q, Ma L, et al. Effect of telmisartan on hypertension patients with paroxysmal atrial fibrillation [In Chinese]. Guangxi Med J 2015;37:614-6.

137. Pang F, Gong YX, Zheng GM. Clinical observation of valsartan in the treatment of hypertension complicated with atrial fibrillation [In Chinese]. Sci Technol Vis 2015;349.

138. Wang B. Clinical observation on efficacy of irbesartan combined with atorvastatin in treatment of hypertension complicated with paroxysmal atrial fibrillation [In Chinese]. Med Recapitulate 2015;21:3972-4.

139. Yan Y, Zhang B, Wang XG, et al. Clinical effect of benazepril combined with amiodarone in patients with paroxysmal atrial fibrillation. China J Pharm Econ 2015;12:38-9.

140. Huang JZ, Peng J, Gao SL. The effects of valsartan on levels of inflammatory factors and left atrial diameter in the elderly patients with hypertension complicated persistent atrial fibrillation [In Chinese]. Prev Treat Cardio Cerebral Vasc Dis 2015;15:107-9.
141. Yuan S, Liu FS. Effects of cotherapy with candesartan cilexetil and rosuvastatin on patients with chronic cardiac insufficiency and paroxysmal atrial fibrillation [In Chinese]. J Precision Med 2015;30:587-9.

142. Chen JK, Zhu PL, Yan Y, et al. Small doses of rivaroxaba prevents stroke in advance-aged type 2 diabetics with atrial fibrillation [In Chinese]. J China Med Univ 2015;44:755-7.

143. Tu HY. Efficacy and safety of warfarin in the treatment of elderly patients with non-valvular atrial fibrillation [In Chinese]. Guide China Med 2016:14:140-1.

144. Bassand J-P, Accetta G, Camm AJ, et al. Two-Year outcomes of patients with newly diagnosed atrial fibrillation: results from GARFIELD-AF. Eur Heart J 2016;37:2882-9.

145. Haas S, ten Cate H, Accetta G, et al. Quality of vitamin K antagonist control and 1-year outcomes in patients with atrial fibrillation: a global perspective from the GARFIELD-AF registry. PLoS One 2016;11:e0164076.

146. Chan $\mathrm{P}-\mathrm{H}$, Huang D, Hai JJ, et al. Stroke prevention using dabigatran in elderly Chinese patients with atrial fibrillation. Heart Rhythm 2016:13:366-73.

147. Chan P-H, Huang D, Lau C-P, et al. Net clinical benefit of dabigatran over warfarin in patients with atrial fibrillation stratified by CHA2DS2-VASc and time in therapeutic range. Can J Cardiol 2016;32:1247.e15-1247.e21

148. Xie L, Vo L, Keshishian A, et al. Comparison of hospital length of stay and hospitalization costs among patients with non-valvular atrial fibrillation treated with apixaban or warfarin: an early view. $J$ Med Econ 2016;19:769-76.

149. Bengtson LGS, Lutsey PL, Chen LY, et al. Comparative effectiveness of dabigatran and rivaroxaban versus warfarin for the treatment of non-valvular atrial fibrillation. J Cardiol 2017;69:868-76.

150. Chan P-H, Hai J-J, Huang D, et al. Burden of upper gastrointestinal symptoms in patients prescribed dabigatran for stroke prevention. SAGE Open Med 2016;4.

151. Hohnloser SH, Basic E, Nabauer M. Comparative risk of major bleeding with new oral anticoagulants (NOACs) and phenprocoumon in patients with atrial fibrillation: a post-marketing surveillance study. Clin Res Cardiol 2017;106:618-28.

152. Saji N, Kimura K, Tateishi Y, et al. Safety and efficacy of non-vitamin $\mathrm{K}$ oral anticoagulant treatment compared with warfarin in patients with non-valvular atrial fibrillation who develop acute ischemic stroke or transient ischemic attack: a multicenter prospective cohort study (daVinci study). J Thromb Thrombolysis 2016;42:453-62.

153. Korenstra J, Wijtvliet EPJ, Veeger NJGM, et al. Effectiveness and safety of dabigatran versus acenocoumarol in 'real-world' patients with atrial fibrillation. Europace 2016;18:1319-27.

154. Naganuma M, Shiga T, Nagao T, et al. Effectiveness and safety of dabigatran versus warfarin in "real-world" Japanese patients with atrial fibrillation: single-center observational study. J Arrhythm 2017;33:107-10.

155. Sunbul M, Oguz M, Dogan Z, et al. Heart failure and mortality in patients with nonvalvular atrial fibrillation started on novel oral anticoagulant therapy: a single-center experience. Clin Appl Thromb Hemost 2017;23:454-9.

156. Yao X, Abraham NS, Sangaralingham LR, et al. Effectiveness and safety of dabigatran, rivaroxaban, and apixaban versus warfarin in nonvalvular atrial fibrillation. J Am Heart Assoc 2016;5:e003725.

157. Ezekowitz MD, Eikelboom J, Oldgren J, et al. Long-Term evaluation of dabigatran 150 vs. $110 \mathrm{Mg}$ twice a day in patients with nonvalvular atrial fibrillation. Europace 2016;18:973-8.

158. Camm AJ, Amarenco P, Haas S, et al. XANTUS: a real-world, prospective, observational study of patients treated with rivaroxaban for stroke prevention in atrial fibrillation. Eur Heart $J$ 2016;37:1145-53

159. Márquez-Contreras E, Martell-Claros N, Gil-Guillén V, et al. Quality of life with rivaroxaban in patients with non-valvular atrial fibrilation by therapeutic compliance. Qual Life Res 2017;26:647-54.

160. Tepper PG, Liu X, Hamilton M, et al. Ischemic stroke in nonvalvular atrial fibrillation at warfarin initiation: assessment via a large insurance database. Stroke 2017;48.

161. Li XY, Deitelzweig S, Keshishian A, et al. Effectiveness and safety of apixaban versus warfarin in non-valvular atrial fibrillation patients in "real-world" clinical practice. Thromb Haemostasis 2017:117:1072-82.

162. Márquez-Contreras E, Martell-Carlos N, Gil-Guillén V, et al. Therapeutic compliance with rivaroxaban in preventing stroke in patients with non-valvular atrial fibrillation: CUMRIVAFA study. Curr Med Res Opin 2016;32:2013-20.

163. Larsen TB, Skjøth F, Nielsen PB, et al. Comparative effectiveness and safety of non-vitamin $\mathrm{K}$ antagonist oral anticoagulants and 
warfarin in patients with atrial fibrillation: propensity weighted nationwide cohort study. BMJ 2016;353.

164. Kilickiran Avci B, Vatan B, Ozden Tok O, et al. The trends in utilizing Nonvitamin $\mathrm{K}$ antagonist oral anticoagulants in patients with nonvalvular atrial fibrillation: a real-life experience. Clin Appl Thromb Hemost 2016;22:785-91.

165. Inoue $\mathrm{H}$, Uchiyama $\mathrm{S}$, Atarashi $\mathrm{H}$, et al. Post-Marketing surveillance on the long-term use of dabigatran in Japanese patients with nonvalvular atrial fibrillation: preliminary report of the $\mathrm{J}$-dabigatran surveillance. J Arrhythm 2016;32:145-50.

166. Chan P-H, Li W-H, Hai J-J, et al. Gastrointestinal haemorrhage in atrial fibrillation patients: impact of quality of anticoagulation control. Eur Heart J Cardiovasc Pharmacother 2015;1:265-72.

167. Laliberté F, Cloutier M, Crivera C, et al. Effects of rivaroxaban versus warfarin on hospitalization days and other health care resource utilization in patients with nonvalvular atrial fibrillation: an observational study from a cohort of matched users. Clin Ther 2015;37:554-62.

168. Lee S-J, Uhm J-S, Kim J-Y, et al. The safety and efficacy of vitamin $\mathrm{K}$ antagonist in patients with atrial fibrillation and liver cirrhosis. Int $J$ Cardiol 2015;180:185-91.

169. Lau WCY, Chan EW, Cheung C-L, et al. Association between dabigatran vs warfarin and risk of osteoporotic fractures among patients with nonvalvular atrial fibrillation. JAMA 2017;317:1151-8.

170. Ho C-W, Ho M-H, Chan P-H, et al. Ischemic stroke and intracranial hemorrhage with aspirin, dabigatran, and warfarin: impact of quality of anticoagulation control. Stroke 2015;46:23-30.

171. Chan P-H, Hai J, Yeung C-Y, et al. Benefit of anticoagulation therapy in Hyperthyroidism-Related atrial fibrillation. Clin Cardiol 2015:38:476-82.

172. Chao T-F, Liu C-J, Tuan T-C, et al. Rate-control treatment and mortality in atrial fibrillation. Circulation 2015;132:1604-12.

173. Pastori D, Farcomeni A, Bucci T, et al. Digoxin treatment is associated with increased total and cardiovascular mortality in anticoagulated patients with atrial fibrillation. Int $\mathrm{J}$ Cardiol 2015;180:1-5

174. Chen P-C, Lip GYH, Yeh G, et al. Risk of bleeding and stroke with oral anticoagulation and antiplatelet therapy in patients with atrial fibrillation in Taiwan: a nationwide cohort study. PLOS One 2015;10:e125257.

175. Engelberger RP, Noll G, Schmidt D, et al. Initiation of rivaroxaban in patients with nonvalvular atrial fibrillation at the primary care level: the Swiss therapy in atrial fibrillation for the regulation of coagulation (STAR) study. Eur J Intern Med 2015;26:508-14.

176. Li H, Liu Y, Zhang P, et al. Analysis of normalized anticoagulant therapy for patients with non-valvular atrial fibrillation in clinical application [In Chinese]. Pract J Med Pharm 2016;33:584-5.

177. Tung JM, Mamdani MM, Juurlink DN, et al. Rates of ischemic stroke during warfarin treatment for atrial fibrillation. Stroke 2015;46:1120-2.

178. Wu Y-L, Saver JL, Chen P-C, et al. Effect of statin use on clinical outcomes in ischemic stroke patients with atrial fibrillation. Medicine 2017;96:e5918.

179. Kodani $\mathrm{E}$, Atarashi $\mathrm{H}$, Inoue $\mathrm{H}$, et al. Beneficial effect of non-vitamin $\mathrm{K}$ antagonist oral anticoagulants in patients with nonvalvular atrial fibrillation- Results of the J-RHYTHM registry 2. Circ $J$ 2016;80:843-51.

180. Yamashita $\mathrm{T}$, Inoue $\mathrm{H}$, Okumura $\mathrm{K}$, et al. Warfarin anticoagulation intensity in Japanese nonvalvular atrial fibrillation patients: a J-RHYTHM registry analysis. J Cardiol 2015;65:175-7.

181. Kumagai $\mathrm{N}$, Nusser JA, Inoue $\mathrm{H}$, et al. Effect of addition of a statin to warfarin on thromboembolic events in Japanese patients with nonvalvular atrial fibrillation and diabetes mellitus. Am J Cardiol 2017:120:230-5.

182. Blin P, Dureau-Pournin C, Lassalle R, et al. A population database study of outcomes associated with vitamin $\mathrm{K}$ antagonists in atrial fibrillation before DOAC. Br J Clin Pharmacol 2016;81:569-78.

183. Piccini JP, Simon DN, Steinberg BA, et al. Differences in clinical and functional outcomes of atrial fibrillation in women and men: two-year results from the ORBIT-AF registry. JAMA Cardiol 2016;1:282-91.

184. Allen LA, Fonarow GC, Simon DN, et al. Digoxin use and subsequent outcomes among patients in a contemporary atrial fibrillation cohort. J Am Coll Cardiol 2015;65:2691-8.

185. Genovesi S, Rossi E, Gallieni M, et al. Warfarin use, mortality, bleeding and stroke in haemodialysis patients with atrial fibrillation. Nephrol Dial Transplant 2015;30:491-8.

186. Qin D, Leef G, Alam MB, et al. Comparative effectiveness of antiarrhythmic drugs for rhythm control of atrial fibrillation. $J$ Cardiol 2016;67:471-6.
187. Purmah Y, Proietti M, Laroche $\mathrm{C}$, et al. Rate vs. rhythm control and adverse outcomes among European patients with atrial fibrillation. Europace 2018;20:243-52

188. Pasca S, Venturelli U, Bertone A, et al. Direct oral anticoagulants for very elderly people with atrial fibrillation: efficacy and safe enough? Clin Appl Thromb Hemost 2017;23:58-63.

189. Nielsen PB, Skjøth F, Søgaard M, et al. Effectiveness and safety of reduced dose non-vitamin $\mathrm{K}$ antagonist oral anticoagulants and warfarin in patients with atrial fibrillation: propensity weighted nationwide cohort study. BMJ 2017;356.

190. Bo M, Li Puma F, Badinella Martini M, et al. Effects of oral anticoagulant therapy in older medical in-patients with atrial fibrillation: a prospective cohort observational study. Aging Clin Exp Res 2017;29:491-7.

191. Jacobs V, May HT, Bair TL, et al. Long-term population-based cerebral ischemic event and cognitive outcomes of direct oral anticoagulants compared with warfarin among long-term anticoagulated patients for atrial fibrillation. Am J Cardiol 2016;118:210-4.

192. Lip GYH, Pan X, Kamble S, et al. Major bleeding risk among nonvalvular atrial fibrillation patients initiated on apixaban, dabigatran, rivaroxaban or warfarin: a "real-world" observational study in the United States. Int J Clin Pract 2016;70:752-63.

193. Hanon O, Chaussade E, Gueranger P, et al. Patient-Reported treatment satisfaction with rivaroxaban for stroke prevention in atria fibrillation. A French observational study, the safari study. PLoS One 2016;11:e166218

194. Patti G, Lucerna M, Pecen L, et al. Thromboembolic Risk, Bleeding Outcomes and Effect of Different Antithrombotic Strategies in Very Elderly Patients With Atrial Fibrillation: A Sub-Analysis From the PREFER in AF (PREvention oF Thromboembolic Events-European Registry in Atrial Fibrillation). J Am Heart Assoc 2017;6:e005657.

195. Graham DJ, Reichman ME, Wernecke M, et al Stroke, bleeding, and mortality risks in elderly Medicare beneficiaries treated with dabigatran or rivaroxaban for nonvalvular atrial fibrillation. JAMA Intern Med 2016;176:1662-71.

196. Tampieri A, Cipriano V, Mucci F, et al. Safety of cardioversion in atrial fibrillation lasting less than $48 \mathrm{~h}$ without post-procedural anticoagulation in patients at low cardioembolic risk. Intern Emerg Med 2018;13:87-93.

197. Lee S-J, Sung J-H, Kim J-B, et al. The safety and efficacy of vitamin $\mathrm{K}$ antagonist in atrial fibrillation patients with previous ulcer bleeding: long-term results from a multicenter study. Medicine 2016;95:e5467.

198. Stolk LM, de Vries F, Ebbelaar C, et al. Risk of myocardial infarction in patients with atrial fibrillation using vitamin $\mathrm{K}$ antagonists, aspirin or direct acting oral anticoagulants. Br J Clin Pharmacol 2017;83:1835-43.

199. Boriani G, Laroche C, Diemberger I, et al. 'Real-world' management and outcomes of patients with paroxysmal vs. non-paroxysmal atrial fibrillation in Europe: the EURObservational research Programme-Atrial fibrillation (EORP-AF) general pilot registry. Europace 2016;18:648.1-57

200. Eisen A, Ruff CT, Braunwald E, et al. Digoxin use and subsequent clinical outcomes in patients with atrial fibrillation with or without heart failure in the engage AF-TIMI 48 trial. J Am Heart Assoc 2017:6:e006035.

201. Wan L, Deng L. Analysis of Anticoagulant Efficacy and Safety of dabigatran combined with clopidogrel in treatment of NVAF [In Chinese]. Mod Hosp 2018;18:536-8.

202. Jian F. The analysis of efficacy and adverse effects of daigatran in treating NVAF [In Chinese]. China Pract Med 2017;12:168-70.

203. Gao DS. Therapeutic effect of different intensity anticoagulant therapy for chronic non-valvular atrial fibrillation in elderly patients [In Chinese]. Guide China Med 2018;16:108-9.

204. Wang Y. Clinical observation of different INR on elderly patients with stable coronary heart disease complicated with atrial fibrillation [In Chinese]. J Aerosp Med 2018;29:317-9.

205. Zhang DM, Zhang HM. Clinical observation of different INR on elderly patients with stable coronary heart disease complicated with atrial fibrillation [In Chinese]. Chongqing Med 2017;46:3420-1.

206. Hasigaowa CZC, Liu DH, Zhang Y W. Effects of Rivaroxaban and Warfarin on D-dimer and NT-proBNP Levels in Elderly Patients with NVAF [In Chinese]. Prog Mod Biomed 2017;17:6291-4.

207. Chen L, Gong YX, Zhang XL. Clinical Effect in Treating Non-valvular Atrial Fibrillation Patients with Advanced Age ( $\geq 80$ Years Old):a Comparison between Rivaroxaban and Warfarin [In Chinese]. Pract $J$ Card Cereb Pneumal Vasc Dis 2018;26:55-8.

208. Chen L, Zhong SQ, Zhong HJ, et al. Effect of Maixuekang Capsule on thromboembolism in patients with non-valvular atrial fibrillation [In Chinese]. Chin J Mod Drug Appl 2018;12:86-7. 
209. Li D, Yue MZ. Clinical observation of Tongluo Dingxin Recipe in the treatment of blood stasis type of non-valvular atrial fibrillation and its effect on coagulation [In Chinese]. Yunnan J Tradit Chin Med Mater Med 2018;39:48-9.

210. Yu P. Clinical observation and safety evaluation of modified Xuefu Zhuyu decoction combined with dabigatran etexilate in the treatment of non - valvular atrial fibrillation. Inform Tradit Chin Med 2018;35:108-10.

211. De With RR, Rienstra M, Smit MD, et al. Targeted therapy of underlying conditions improves quality of life in patients with persistent atrial fibrillation: results of the RACE 3 study. Europace 2019;21:563-71.

212. Ezekowitz MD, Pollack CV, Halperin JL, et al. Apixaban compared to heparin/vitamin $\mathrm{K}$ antagonist in patients with atrial fibrillation scheduled for cardioversion: the EMANATE trial. Eur Heart $J$ 2018;39:2959-71.

213. Li XL, Lu Y, Yin JF, et al. Genotype-Based anticoagulant therapy with warfarin for atrial fibrillation. Int J Clin Exp Med 2017;10:14056-62.

214. Yamashita T, Ikeda T, Akita Y. Comparison of heart rate reduction effect and safety between bisoprolol transdermal patch and bisoprolol fumarate oral formulation in Japanese patients with persistent/permanent atrial fibrillation (BISONO-AF study). J Cardiol 2019;73:386-93.

215. Bartlett JW, Renner E, Mouland E, et al. Clinical safety outcomes in patients with nonvalvular atrial fibrillation on rivaroxaban and diltiazem. Ann Pharmacother 2019;53:21-7.

216. Andersson NW, Svanström H, Lund M, et al. Comparative effectiveness and safety of apixaban, dabigatran, and rivaroxaban in patients with non-valvular atrial fibrillation. Int $J$ Cardiol 2018:268:113-9.

217. Deitelzweig S, Luo X, Gupta K, et al. Comparison of effectiveness and safety of treatment with apixaban vs. other oral anticoagulants among elderly nonvalvular atrial fibrillation patients. Curr Med Res Opin 2017;33:1745-54

218. Friberg L, Oldgren J. Efficacy and safety of non-vitamin $\mathrm{K}$ antagonist oral anticoagulants compared with warfarin in patients with atrial fibrillation. Open Heart 2017;4:e682.

219. Hernandez I, Zhang Y, Saba S. Comparison of the effectiveness and safety of apixaban, dabigatran, rivaroxaban, and warfarin in newly diagnosed atrial fibrillation. Am J Cardiol 2017;120:1813-9.

220. Pohjantähti-Maaroos H, Hyppölä $\mathrm{H}$, Lekkala M, et al. Intravenous vernakalant in comparison with intravenous flecainide in the cardioversion of recent-onset atrial fibrillation. Eur Heart $J$ 2019;8:114-20.

221. Koretsune Y, Yamashita T, Yasaka M, et al. Comparative effectiveness and safety of warfarin and dabigatran in patients with non-valvular atrial fibrillation in Japan: a claims database analysis. $J$ Cardiol 2019;73:204-9.
222. Lai K-C, Chen S-J, Lin C-S, et al. Digoxin and amiodarone on the risk of ischemic stroke in atrial fibrillation: an observational study. Front Pharmacol 2018;9:448.

223. Li W-H, Huang D, Chiang C-E, et al. Efficacy and safety of dabigatran, rivaroxaban, and warfarin for stroke prevention in Chinese patients with atrial fibrillation: the Hong Kong atrial fibrillation project. Clin Cardiol 2017:40:222-9.

224. Link MS, Giugliano RP, Ruff CT, et al. Stroke and mortality risk in patients with various patterns of atrial fibrillation: results from the engage AF-TIMI 48 trial (effective anticoagulation with factor Xa next generation in atrial Fibrillation-Thrombolysis in myocardial infarction 48). Circ Arrhythm Electrophysiol 2017;10:e004267.

225. Lip GYH, Skjøth F, Nielsen PB, et al. Effectiveness and safety of standard-dose Nonvitamin $\mathrm{K}$ antagonist oral anticoagulants and warfarin among patients with atrial fibrillation with a single stroke risk factor: a nationwide cohort study. JAMA Cardiol 2017;2:872-81.

226. Noseworthy PA, Yao X, Gersh BJ, et al. Long-Term stroke and bleeding risk in patients with atrial fibrillation treated with oral anticoagulants in contemporary practice: providing evidence for shared decision-making. Int J Cardiol 2017;245:174-7.

227. Lip GYH, Keshishian A, Li X, et al. Effectiveness and safety of oral anticoagulants among nonvalvular atrial fibrillation patients. Stroke 2018;49:2933-44.

228. Martinez BK, Bunz TJ, Eriksson D, et al. Effectiveness and safety of rivaroxaban vs. warfarin in patients with non-valvular atrial fibrillation and heart failure. ESC Heart Fail 2019;6:10-15.

229. Gieling EM, van den Ham HA, van Onzenoort $\mathrm{H}$, et al. Risk of major bleeding and stroke associated with the use of vitamin $\mathrm{K}$ antagonists, nonvitamin $\mathrm{K}$ antagonist oral anticoagulants and aspirin in patients with atrial fibrillation: a cohort study. Br J Clin Pharmacol 2017;83:1844-59.

230. Go AS, Singer DE, Toh S, et al. Outcomes of dabigatran and warfarin for atrial fibrillation in contemporary practice: a retrospective cohort study. Ann Intern Med 2017;167:845-54.

231. Forslund $T$, Wettermark $B$, Andersen $M$, et al. Stroke and bleeding with non-vitamin $\mathrm{K}$ antagonist oral anticoagulant or warfarin treatment in patients with non-valvular atrial fibrillation: a population-based cohort study. Europace 2018;20:420-8.

232. Själander S, Sjögren V, Renlund $\mathrm{H}$, et al. Dabigatran, rivaroxaban and apixaban vs. high TTR warfarin in atrial fibrillation. Thromb Res 2018;167:113-8.

233. Corbalán R, Nicolau JC, López-Sendon J, et al. Edoxaban versus Warfarin in Latin American patients with atrial fibrillation: the ENGAGE AF-TIMI 48 trial. J Am Coll Cardiol 2018;72:1466-75.

234. Bae $\mathrm{H}-\mathrm{J}$, Heo JH, Jung $\mathrm{K}-\mathrm{H}$, et al. Antithrombotic treatments in patients with acute ischemic stroke and non-valvular atrial fibrillation before introduction of non-vitamin $\mathrm{K}$ antagonist oral anticoagulants into practice in Korea. PLoS One 2018;13:e202803. 